ERJ

Engineering Research Journal Faculty of Engineering

Minoufiya University

\title{
BEHAVIOUR OF REINFORCED CONCRETE FLAT PLATES WITH DROP PARTS
}

\author{
Mohamed H. Matthana, Attia H. Bayomy, A.H. Abdel-Reheem, Ayman Mashaly \\ Structural Engineering Department, Faculty of Engineering, \\ EL-Mansoura University, Egypt
}

\begin{abstract}
This paper presents both experimental and analytical investigations for the behaviour of flat plates provided with drop parts formed by partially decreasing both top and bottom fibers of the plate. The experimental study considers six plate specimens one of them is kept flat without any drop parts to be the control case. The other specimens are provided with drop parts having the same thickness of the plate while they are located at different locations of the plate. The locations of the drops parts considered in the present study are the intersections of two middle strips, two column strips and one middle-one column strips. All plates have the same thickness and the same aspect ratio of 1.0. The plate specimens are supported on four concrete short columns located at the four corners of the plate. The plates are subjected to uniformly-distributed flexural loading where the cracking loads, the cracking patterns in both sides after failure, and the ultimate load are reported. The Plate specimens are then taken up for a detailed nonlinear finite element analysis where the various types of stresses are obtained. The cracking patterns and the load-deflection behaviour are theoretically predicted for various plates. The study shows that the presence of drop parts in flat plates has a significant effect on the mode of failure of the plate while this effect depends on the location of the drop part. The stress distribution within the plate, the cracking and failure patterns and the load-deflection behaviour of various plate specimens are also sensitive to the presence of drop parts.

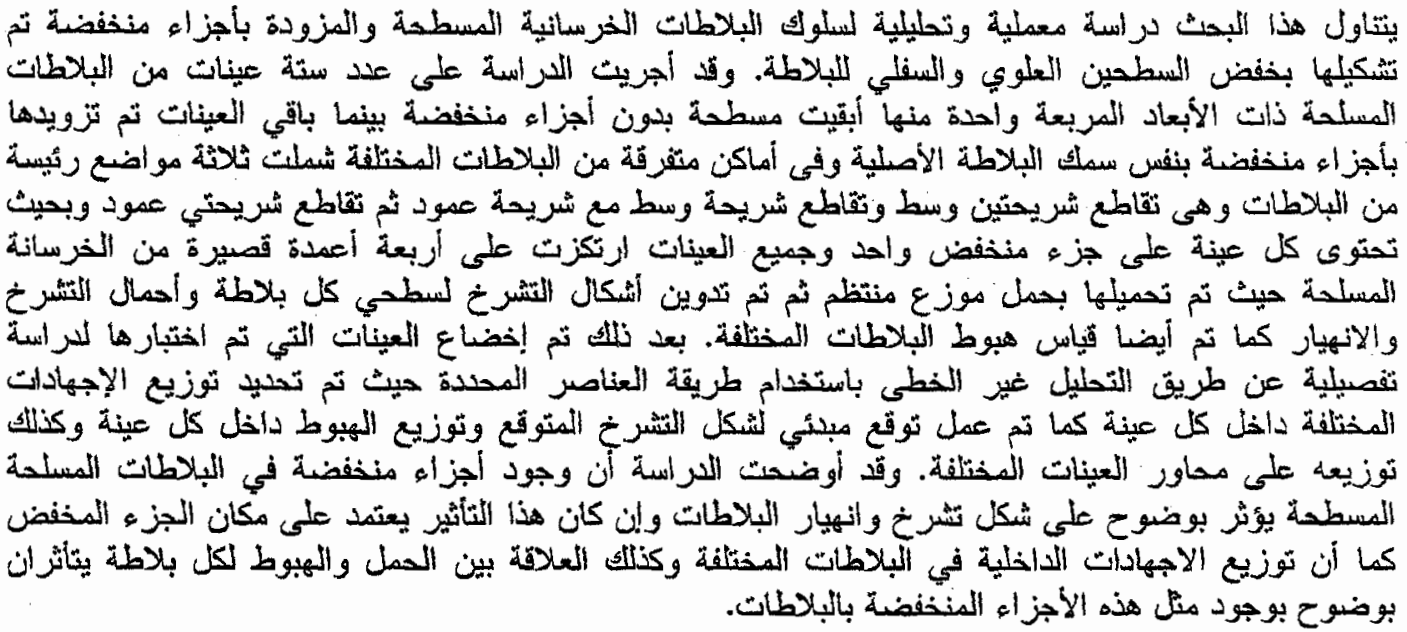

Keywords: Reinforced Concrete, Flat Slabs, Flat Plates, Plates, Drop Parts \& Non-Linear Finite Element.

\section{INTRODUCTION}

Flat slab systems refer to beamless slab systems with direct support at column-slab joints. Due to the direct support of slab on columns, the slab develops shear stress concentration at the regions around the supporting columns. To prevent the slab failure, because of the punching shear, the slab thickness is sometimes partially increased in the region around columns. The partial increase in the slab thickness around columns is usually defined as a drop panel. If the drop panel is not used, the slab will be of uniform thickness and is referred to as flat plate. In some cases, the top surface of the flat plate has to be partially decreased in some regions to meet some 
architectural requirements such as the existence of bath rooms or kitchens. In those cases, the architectural requirements may be fulfilled by decreasing the top surface and increasing the entire thickness of the plate or decreasing both top and bottom surfaces to keep the minimum thickness required for the structural requirements. In the later case, the flat plate is then provided with drop parts. The presence of such drop parts affects the behaviour of flat plates. Few studies are found in the literature concerning the behaviour of flat plates with drop parts. Ghali and Megally, (1999), presented a design procedure for the connections of columns to flat plates to insure safety against punching failure. ElSalakawy et. Al., (1999), studied the behaviour of flat plate edge connections with an opening in the vicinity of the column through six full-scale plate specimens. Carl Erik Broms, (2000), proposed a design concept to eliminate the punching failure mode of flat plates. Abd El Baki, O. F., (2002), studied the behaviour of flat plates with a drop part at the middle zone. He derived an equation to estimate the deflection of such plates and compared the results of this equation with a finite element analysis. This paper presents both experimental and analytical studies as an attempt to understand the effect of drop parts on the behaviour of flat plates. The experimental study includes six plate specimens one of them is kept flat without any drop parts to be the control case, while the other specimens are provided with drop parts having the same thickness of the plate, while they are located at different locations of the plate. The locations of the drops parts considered in the present study are the intersections of two middle strips, two column strips and one middle-one column strips. All plates have the same thickness and the same aspect ratio of 1.0 . The plate specimens are supported on four concrete short columns located at the four corners of the plate. The plates are subjected to uniformly-distributed flexural loading where the cracking loads, the cracking patterns in both sides after failure, and the ultimate load are reported. Plate specimens with drop parts are then taken up for a detailed nonlinear finite element analysis where the various types of stresses are obtained. The cracking patterns and the load-deflection behaviour are also predicted for various plates.

\section{DETAILS OF THE EXPERIMENTAL STUDY}

\subsection{Details of the Test Specimens}

The test specimens, used in the present experimental study, include six plates. One of the test plates is kept flat without any drop parts to be the control specimen while the other five plates are divided into three categories. The first category includes one plate specimen provided with a drop part located at the intersection of two middle (field) strips; (M-M) while the second group includes three specimens provided with drop parts at the intersection of one middle and one column strips; group (M-C). The last category of plate specimens includes one specimen where the drop part is located at the intersection of two column strips; (C-C). The aspect ratio of all plate specimens is kept constant at 1.0. All specimens have the same dimensions of $125 \times 125 \mathrm{~cm}^{2}$ and $5.0 \mathrm{~cm}$ thickness. Each plate specimen is provided with reinforcing steel wires with $3.4 \mathrm{~mm}$ diameter arranged at a spacing of $5.0 \mathrm{~cm}$ and located at suitable zones according to the plate configurations. The plates are supported on four reinforced concrete columns located at the four corners of each plate. Each column has a square cross section with the dimensions of $10 \times 10 \mathrm{~cm}^{2}$ and a clear height of 25 $\mathrm{cm}$ while the column is provided with four longitudinal bars each of $8.0 \mathrm{~mm}$ diameter and stirrups with $3.4 \mathrm{~mm}$ diameter arranged at a spacing of $5.0 \mathrm{~cm}$. The details of various plate specimens are given in Table (1) while Figures (1) and (2) show the configurations of the tested plate specimens.

\section{2 Materials}

Normal strength concrete with an average compressive strength of $35 \mathrm{MPa}\left(350 \mathrm{~kg} / \mathrm{cm}^{2}\right)$ is used for all plate specimens. Fine aggregate from natural sand is used. The used sand was clean and free from impurities, silt, and clay. The coarse aggregate used in the present investigation was natural gravel with a nominal maximum size of $9.51 \mathrm{~mm}$ (3/8 inch). Gravel batches employed was clean and free from injurious matter. The same ordinary Portland cement is used along with potable water in all specimens. The compressive strength of the used concrete is measured through $15 \times 15 \times 15 \mathrm{~cm}^{3}$ concrete cubes where an average value of $350 \mathrm{~kg} / \mathrm{cm}^{2}$ is obtained. Cylindrical concrete specimens with $15 \mathrm{~cm}$ diameter and $30 \mathrm{~cm}$ height are used for the measurements of the splitting tensile strength and the modulus of elasticity. The tested concrete cylinders have shown an average value for the tensile strength of 28.9 $\mathrm{kg} / \mathrm{cm}^{2}$ while the average value of the modulus of elasticity is found to be $193746 \mathrm{~kg} / \mathrm{cm}^{2}$. Mechanical mixing and mechanical compacting in steel moulds using a table vibrator is maintained for all mixes used for the determination of the properties of used concrete. Wooden forms with dimensions of $125 \times 125$ $\mathrm{cm}^{2}$ are used for casting plate specimens. At the beginning of the mixing process of concrete, the constituents were mixed in its dry state to insure the uniformity of the mix. Mixing water was then added gradually and the contents were mixed in a vertical axis drum mixer for a period of two minutes. Both Mixing and casting processes of concrete are carried out at room temperature. All moulds are removed after 24 hours from casting and the concrete specimens are kept in water for 28 days for curing while the plate specimens are kept under damp jute bags for 28 days for curing. The Egyptian code and 
standards [3-8] are followed. The details of concrete mix are summarized in Table (2). Mild steel wires with $3.4 \mathrm{~mm}$ diameter are used in the reinforcement of all plate specimens. Three wire specimens are subjected to tensile tests to evaluate the yield strength, the ultimate strength and the elongation percent. The results are presented in Table (3). The tensile test of the steel reinforcement was carried out according to the Egyptian Standards E.C.C.S (2032001).

\subsection{Test Procedure}

All plate specimens are tested in a loading frame under uniformly distributed compressive loading. A concentrated load from a 60 ton capacity hydraulic jack was transferred to the plate specimen through a grid system of steel beams. Wooden blocks of $10 \times 10 \times 5 \mathrm{~cm}^{3}$ are used to transfer the load from the grid of steel beams to the top surface of the plate specimen as a distributed load. Figure (3) shows the configurations of the loading system, while the photo of the complete experimental set-up is shown in Plate (1). The deflection of the tested plate specimen is monitored through a mechanical dial gauge of 0.01 $\mathrm{mm}$ accuracy and a total capacity of $50.0 \mathrm{~mm}$ located at the center of the plate. Load is applied in small increments and all the deflection readings are manually recorded at the end of each load increment. The initiation and propagation of bottom cracks were marked and the mode of failure was noted after final collapse. The initiation of cracks at the top surface of the plate specimens could not be accurately marked because of the arrangements of the loading system at the top surface of the plate, while the cracking pattern of the top surface was reported after failure.

\section{DETAILS OF THE NONLINEAR FINITE ELEMENT ANALYSIS}

3.1 Type of Analysis, Element Type, Meshing, and Solution Technique

A detailed nonlinear finite element study is carried out. The study considered the effect of material nonlinearity while, the effect of large strain and large deflection did not considered. The stress-stiffening effects are not also taken into consideration. A three dimensional nonlinear finite element model is utilized for each plate. The computer program ANSYS is used for the analysis of various models. The body of the plate is modeled using a three dimensional reinforced concrete element called

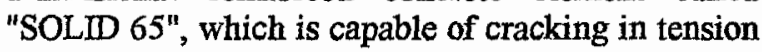
and crushing in compression while, the main and web reinforcements are modeled through a bar element within the "SOLID 65 " element. The bar element is assumed to be smeared within the concrete solid element. The "SOLID 65" element geometry, node locations, and the element coordinate system are shown in Fig. (4). As shown in Fig. (4), the element is defined by eight nodes having three translational degrees of freedom $(x, y$, and $z)$ at each node and it can handle only one solid material. The bar elements which are assumed be smeared within the solid element may be defined through the rebar specifications which include the material type, the volume ratio, and the orientation angles. The volume ratio is defined as the rebar volume divided by the total solid element volume. The orientation is defined by two angles measured from the element coordinate system. The "SOLID 65" element can handle up to three rebar materials. The most important aspect of the "SOLID 65" element is the treatment of nonlinear material properties. The concrete is capable of cracking (in three orthogonal directions), crushing, plastic deformation, and creep. The rebars are capable of tension, and compression, but not shear. They are also capable of plastic deformation and creep. Each plate is meshed according to its details and reinforcement. The solid element is used to model the concrete body, while the embedded bars are used to model the steel reinforcement. The configurations of various finite element models of various plate specimens with drop parts are shown in Fig. (5). The "SOLID 65" element is nonlinear and requires an iterative solution. As both cracking and crushing are used together in the present analysis, the load has been applied slowly to prevent possible fictitious crushing of concrete before proper load transfer can occur through a closed crack. This usually happens when excessive cracking strains are coupled to the orthogonal un-cracked directions through Poisson's effect. Also, at those integration points where crushing has occurred, the output plastic and creep strains are from the previous converged sub step. Furthermore, when cracking has occurred, the elastic strain output includes the cracking strain. The lost shear resistance of cracked and / or crushed elements cannot be transferred to the rebars, which have no shear stiffness. Therefore, the automatic time stepping technique is used. This technique is one in which the time size or the applied loads are automatically determined in response to the current state of the analysis under consideration. There are two features of the automatic time stepping. The first feature concerns the ability to estimate the next time step size based on the current and past analysis conditions, and make proper load adjustments. The second feature is referred to as the time step bisection component. Its purpose is to decide whether or not reduce the present time step size, and redo the sub step with a smaller step size. The program also considers the effect of the shear transfer at both closed and open cracks. Typical shear transfer coefficient ranges from $(0.0$ to 1.0$)$ with $(0.0)$ representing a smooth crack, which means a complete loss of shear transfer, and (1.0) representing a rough crack which means no loss of shear transfer 
may be used while, the first case is used in the present study. As basic assumptions, cracking is permitted in three orthogonal directions at each integration point. If cracking occurs at an integration point, the cracking is modeled through an adjustment of material properties which effectively treats cracking as a smeared band of cracks, rather than discrete cracks. The concrete material is assumed to be initially isotropic. The lost shear resistance of cracked and/or crushed elements can not be transferred to the rebars, which have no shear stiffness.

\subsection{Material Model for Concrete}

The concrete material is modeled using a special model for granular materials. Both cracking and crushing failure modes are accounted for. The failure criterion of concrete due to multi-axial stress state is expressed by the Wiiliam and Warnke (11) model as follows:

where:

$$
F / f_{c}-S \geq 0
$$

F is the function of the principal stress state $\left(\sigma_{\mathrm{xp}}\right.$, $\left.\sigma_{y p}, \sigma_{z p}\right)$.

$S$ is the failure surface which is expressed in terms of principal stresses and five input parameters $\left(f_{t}\right.$,

$f_{c}, f_{c b}, f_{1}$, and $f_{2}$ ).

$f_{t}$ is the ultimate uni-axial tensile strength.

$f_{c}$ is the ultimate uni-axial compressive strength.

$f_{c b}$ is the ultimate bi-axial compressive strength.

$f_{1}$ is the ultimate compressive strength for a state of bi-axial compression superimposed on hydrostatic stress state.

$\mathrm{f}_{2}$ is the ultimate compressive strength for a state of uni-axial compression superimposed on hydrostatic stress state.

The failure surface can be specified with a minimum of two constants $\left(f_{t}\right.$ and $\left.f_{c}\right)$ and, thus, the other three constants default as given by William and Warnke (12) as follows:

$$
\mathrm{f}_{\mathrm{cb}}=1.2 \mathrm{f}_{\mathrm{c}} \quad \mathrm{f}_{1}=1.45 \mathrm{f}_{\mathrm{c}} \quad \mathrm{f}_{2}=1.725 \mathrm{f}_{\mathrm{c}}
$$

However, these default values are valid only for stress states where the following condition is

$$
\text { satisfied: }
$$

$$
\left|\sigma_{h}\right| \leq \sqrt{3 f_{c}}
$$

where, $\sigma_{\mathrm{h}}$ is the hydrostatic stress state defined as:

$$
\sigma_{\mathrm{h}}=1 / 3\left(\sigma_{\mathrm{xp}}+\sigma_{\mathrm{yp}}+\sigma_{\mathrm{zp}}\right)
$$

Both the function $F$ and the failure surface $S$ are expressed in terms of principal stresses denoted as: $\sigma_{1}, \sigma_{2}$, and $\sigma_{3}$ where,

$$
\begin{aligned}
& \sigma_{1}=\max \left(\sigma_{x p}, \sigma_{y p}, \sigma_{z p}\right) \\
& \sigma_{3}=\min \left(\sigma_{x p}, \sigma_{y p}, \sigma_{z p}\right),
\end{aligned}
$$$$
\text { and } \quad \sigma_{1} \geq \sigma_{2} \geq \sigma_{3} \text {. }
$$

The failure of concrete is categorized into four domains:
(1) $\left(0 \geq \sigma_{1} \geq \sigma_{2} \geq \sigma_{3}\right)$

compression-compression-compression (C-C-C).

(2) $\left(\sigma_{1} \geq 0 \geq \sigma_{2} \geq \sigma_{3}\right)$ tension-compression-compression ( $\mathrm{T}-\mathrm{C}-\mathrm{C})$.

(3) $\left(\sigma_{1} \geq \sigma_{2} \geq 0 \geq \sigma_{3}\right)$ tension-tension-compression (T-T-C).

(4) $\left(\sigma_{1} \geq \sigma_{2} \geq \sigma_{3} \geq 0\right)$ tension- tension- tension (T-T-T).

In each domain, independent functions describe the State of stress (F) and the failure surface (S). The four functions describing the general function $(F)$ are denoted $F_{1}, F_{2}, F_{3}$, and $F_{4}$ while, the functions describing the failure surface (S) are denoted as $S_{1}$, $S_{2}, S_{3}$, and $S_{4}$. The functions $S_{i}(i=1,4)$ have the properties that the surface they describe is continuous while the surface gradients are not continuous when anyone of the principle stresses change sign. The surface is shown in Figures (6-8).

\section{For the Compression-Compression-Compression}

Domain; ( $\left(0 \geq \sigma_{1} \geq \sigma_{2} \geq \sigma_{3}\right)$

The function $\mathrm{F}$ takes the form:

$$
F=F_{1}=\frac{1}{\sqrt{15}}\left[\left(\sigma_{1}-\sigma_{2}\right)^{2}+\left(\sigma_{2}-\sigma_{3}\right)^{2}+\left(\sigma_{3}-\sigma_{1}\right)^{2}\right]^{0.5}
$$

and $S$ is defined as:

$$
\begin{aligned}
S=S_{1}= & \frac{2 r_{2}\left(r_{2}^{2}-r_{1}^{2}\right) \cos \eta}{4\left(r_{2}^{2}-r_{1}^{2}\right) \cos ^{2} \eta+\left(r_{2}-2 r_{1}\right)^{2}} . \\
& +\frac{r_{2}\left(2 r_{1}-r_{2}\right)\left[4\left(r_{2}^{2}-r_{1}^{2}\right) \cos ^{2} \eta+5 r_{1}^{2}-4 r_{1} r_{2}\right] 0.5}{4\left(r_{2}^{2}-r_{1}^{2}\right) \cos ^{2} \eta+\left(r_{2}-2 r_{1}\right)^{2}}(6)
\end{aligned}
$$

where:

$$
\cos \eta=\frac{2 \sigma_{1}-\sigma_{2}-\sigma_{3}}{\sqrt{2}\left[\left(\sigma_{1}-\sigma_{2}\right)^{2}+\left(\sigma_{2}-\sigma_{3}\right)^{2}+\left(\sigma_{3}-\sigma_{1}\right)^{2}\right]^{0.5}}
$$

$\mathrm{I}_{1}=\mathrm{a}_{0}+\mathrm{a}_{1} \xi+\mathrm{a}_{2} \xi^{2} \mathrm{x}_{2}=\mathrm{b}_{0}+\mathrm{b}_{1} \xi+\mathrm{b}_{2} \xi^{2} \xi=\sigma_{\mathrm{h}} / \mathrm{f}_{\mathrm{c}}(8)$

$\sigma_{\mathrm{h}}$ is defined by equation (4) and the undetermined coefficients $a_{0}, a_{1}, a_{2}, b_{0}, b_{1}$, and $b_{2}$ are discussed in the following. The failure surface is shown in Figure (6). The angle of similarity $(\eta)$ describes the relative magnitudes of the principle stresses. From equation (7), $\eta=0$ refers to any stress state such that $\sigma_{3}=\sigma_{2}>$ $\sigma_{1}$ (such as uni-axial compression, bi-axial tension) while $\xi=60^{\circ}$ for any stress state where $\sigma_{3}>\sigma_{2}=\sigma_{1}$ (such as uni-axial tension, bi-axial compression). All other multiaxial stress states have angles of similarity such that $0^{\circ} \leq \eta \leq 60^{\circ}$. When $\eta=0^{\circ}, S_{1}$ (equation 6) equals $r_{1}$ while if $\eta=60^{\circ}, S_{1}$ equals $r_{2}$. Therefore, the function $r_{1}$ represents the failure surface of all stress states with $\eta=0^{\circ}$. The functions $r_{1}, r_{2}$ and the angle $\eta$ are depicted on Figure (6). It may be seen that the cross section of the failure plane has cyclic symmetry about each $120^{\circ}$ sector of the octahedral 
plane due to the range $0^{\circ} \leq \eta \leq 60^{\circ}$ of the angle of similitude. The function $r_{1}$ is determined by adjusting $a_{0}, a_{1}$, and $a_{2}$ such that $f_{t}, f_{c b}$, and $f_{1}$ all lie on the failure surface. The proper values for these coefficients are determined through solution of the simultaneous equations:

$$
\left\{\begin{array}{l}
\frac{F_{1}}{f_{c}}\left(\sigma_{1}=f_{t}, \sigma_{2}=\sigma_{3}=0\right) \\
\frac{F_{1}}{f_{c}}\left(\sigma_{1}=0, \sigma_{2}=\sigma_{3}=-f_{c b}\right) \\
\frac{F_{1}}{f_{c}}\left(\sigma_{1}=-\sigma_{h}^{a}, \sigma_{2}=\sigma_{3}=-\sigma_{h}^{a}-f_{1}\right)
\end{array}\right\}=\left[\begin{array}{ccc}
1 & \xi_{t} & \xi_{t}^{2} \\
1 & \xi_{c b} & \xi_{c b}^{2} \\
1 & \xi_{1} & \xi_{1}^{2}
\end{array}\right]\left\{\begin{array}{l}
a_{0} \\
a_{1} \\
a_{2}
\end{array}\right\}
$$

with

$$
\xi_{t}=\frac{f_{t}}{3 f_{c}} \quad \xi_{c b}=-\frac{2 f_{c b}}{3 f_{c}} \quad \xi_{1}=-\frac{\sigma_{h}^{a}}{f_{c}}-\frac{2 f_{1}}{3 f_{c}}
$$

The function $r_{2}$ is calculated by adjusting $b_{0}, b_{i}$, and $b_{2}$ to satisfy the conditions:

$$
\left\{\begin{array}{l}
\frac{F_{1}}{f_{c}}\left(\sigma_{1}=\sigma_{2}=0, \sigma_{3}=-f\right) \\
\frac{F_{1}}{f_{c}}\left(\sigma_{1}=\sigma_{2}=-\sigma_{h}^{a}, \sigma_{3}=\sigma_{h}^{a}-\frac{f_{2}}{f_{c}}\right.
\end{array}\right\}=\left[\begin{array}{ccc}
1 & -\frac{1}{3} & \frac{1}{9} \\
1 & \xi_{2} & \xi_{2}^{2} \\
1 & \xi_{0} & \xi_{0}^{2}
\end{array}\right]\left\{\begin{array}{l}
b_{0} \\
b_{1} \\
b_{2}
\end{array}\right\}
$$

$\xi_{2}$ is defined by: $\quad \xi_{2}=-\frac{\sigma_{h}^{a}}{f_{c}}-\frac{f_{2}}{3 f_{c}}$

and $\xi_{0}$ is the positive root of the equation:

$$
r_{2}\left(\xi_{0}\right)=a_{0}+a_{1} \xi_{0}+a_{2} \xi_{0}^{2}=0
$$

where, $a_{0}, a_{1}$, and $a_{2}$ are evaluated by equation (9). Since the failure surface must remain convex, the ratio $r_{1} / r_{2}$ is restricted to the range:

$$
0.5<\mathrm{r}_{1} / \mathrm{r}_{2}<1.25
$$

Although the upper bound is not considered to be restrictive since $r_{1} / r_{2}<1$ for most materials, also the coefficients $a_{0}, a_{1}, a_{2}, b_{0}, b_{1}$ and $b 2$ must satisfy the conditions (Wiiliam and Warnake (11)):

$a_{0}>0 \quad a_{1} \leq 0 \quad a_{2} \leq 0 \quad b_{0}>0 \quad b_{1} \leq 0 \quad b_{2} \leq 0$

Therefore, the failure surface is closed and predicts failure under high hydrostatic pressure $\xi_{>}>\xi_{2}$. This closure of the failure surface has not been verified experimentally and it has been suggested that Von Misses type cylinder is a more valid failure surface for large compressive $\sigma_{\mathrm{h}}$ values (Wiiliam and Warnake (11)). Consequently, it is recommended that the values of $f_{1}$ and $f_{2}$ are selected at hydrostatic stress level $\left(\sigma_{h}^{a}\right)$ in the vicinity of ore above the expected maximum hydrostatic stress encountered in the structure. Equation (13) expresses the condition that the failure surface has an apex at $\xi=\xi_{0}$. A profile of $r_{1}$ and $r_{2}$ as a function of $\xi$ is shown in
Figure (7). As shown in figure, the lower curve represents all stress states such that $\eta=0^{\circ}$ while the upper curve represents stress states such that $\eta=60^{\circ}$. If the failure criterion is satisfied, the material is assumed to crush.

\section{For the Tension-Compression-Compression}

Domain; $\left(\sigma_{1} \geq 0 \geq \sigma_{2} \geq \sigma_{3}\right)$

The function $\mathrm{F}$ takes the form:

$$
F=F_{2}=\frac{1}{\sqrt{15}}\left[\left(\sigma_{2}-\sigma_{3}\right)^{2}+\sigma_{2}^{2}-\sigma_{3}^{2}\right] 0.5
$$

and $S$ is defined as:

$$
\begin{aligned}
S=S_{2} & =\left(1-\frac{\sigma_{1}}{f_{t}}\right) \frac{2 p_{2}\left(p_{2}^{2}-p_{1}^{2}\right) \cos \eta}{4\left(p_{2}^{2}-p_{1}^{2}\right) \cos ^{2} \eta+\left(p_{2}-2 p_{1}\right)^{2}} \\
& +\frac{p_{2}\left(2 p_{1}-p_{2}\right)\left[4\left(p_{2}^{2}-p_{1}^{2}\right) \cos ^{2} \eta+5 p_{1}^{2}-4 p_{1} p_{2}\right]^{0.5}}{4\left(p_{2}^{2}-p_{1}^{2}\right) \cos ^{2} \eta+\left(p_{2}-2 p_{1}\right)^{2}}
\end{aligned}
$$

where $\cos \eta$ is defined by equation (7) and

$$
\begin{aligned}
& \mathbf{P}_{1}=a_{0}+a_{1} \chi+a_{2} \chi^{2} \\
& \left(\mathbf{P}_{2}=\mathbf{b}_{0}+b_{1} \chi+b_{2} \chi^{2} \quad \text { While } \chi=\left(\sigma_{2}+\sigma_{3}\right) / 3\right.
\end{aligned}
$$

If the failure criterion is satisfied, cracking occurs in the plane perpendicular to the principle stress $\sigma_{1}$.

For the Tension-Tension-Compression Domain; $\left(\sigma_{1} \geq \sigma_{2} \geq 0 \geq \sigma_{3}\right)$

The function $\mathrm{F}$ takes the form:

$$
\mathrm{F}=\mathrm{F}_{3}=\sigma_{i} ; \quad \mathrm{i}=1,2
$$

and $\mathrm{S}$ is defined as:

$$
\mathrm{S}=\mathrm{S}_{3}=\frac{\mathrm{f}_{\mathrm{t}}}{\mathrm{f}_{\mathrm{c}}}\left(1+\frac{\sigma_{3}}{\mathrm{~S}_{2}\left(\sigma_{\mathrm{i}}, 0, \sigma_{3}\right)}\right) ; \mathrm{i}=1,2
$$

If the failure criterion for both $i=1,2$ is satisfied, cracking occurs in the planes perpendicular to principle stresses $\sigma_{1}, \sigma_{2}$. If the failure criterion is satisfied only for $i=1$, cracking occurs only in the plane perpendicular to principle stress $\sigma_{1}$.

For the Tension- Tension- Tension Domain;

$\left(\sigma_{1} \geq \sigma_{2} \geq \sigma_{3} \geq 0\right)$

The function $F$ takes the form: $\quad \xi>\xi_{2}$

$$
F=F_{4}=\sigma_{i} ; i=1,2,3
$$

and $S$ is defined as: $S=S_{4}=f_{t} / f_{c}$

If the failure criterion is satisfied in directions 1,2 and 3, cracking occurs in the planes perpendicular to principle stresses $\sigma_{1}, \sigma_{2}$, and $\sigma_{3}$. If the failure criterion is satisfied in directions 1 , and 2, cracking occurs in the plane perpendicular to principle stresses $\sigma_{1}$, and $\sigma_{2}$. If the failure criterion is satisfied only in direction 1, cracking occurs in the plane perpendicular to principle stress $\sigma_{1}$. Figure (8) represents the $3-D$ failure surface for states of stress 
that are biaxial or nearly biaxial. If the most significant nonzero principle stresses are in the $\sigma_{x p}$ and $\sigma_{y p}$ directions, the three surfaces presented are for $\sigma_{z p}$ slightly grater than zero, $\sigma_{z p}$ equal to zero, and $\sigma_{\text {zp }}$ slightly less than zero. Although the three surfaces, shown as projections on the $\sigma_{\mathrm{xp}}-\sigma_{\mathrm{yp}}$ plane, are nearly equivalent and the 3-D failure surface is continuous, the mode of material failure is a function of the sign of $\sigma_{\mathrm{zp}}$. For example, if $\sigma_{\mathrm{xp}}$ and $\sigma_{\mathrm{yp}}$ are both negative and $\sigma_{z p}$ is slightly positive, cracking would be predicted in a direction perpendicular to the $\sigma_{2 p}$ direction. However, if $\sigma_{\mathrm{zp}}$ is zero or slightly negative, the material is assumed to crush.

\section{RESULTS, DISCUSSIONS, AND MAJOR OBSERVATIONS}

\section{Stress Distributions, Cracking Patterns, Cracking Loads, and Ultimate Loads of Various Plate Specimens}

Figure (9) shows contour lines for the stress distributions within the bodies of various plate specimens and both predicted and experimental cracking patterns of such plates while, the experimental values of both cracking and ultimate loads are summarized in Table (4). As a general notice, the cracking patterns of various plate specimens show extensive cracking on the bottom surface of plates, while the cracks on the top surfaces are concentrated around the supporting columns. This agrees with the cracking patterns expected for simply supported flat plates. For the plate specimen provided with a drop part located at the intersection of two middle strips (M-M), the normal stresses; $\sigma_{x} \& \sigma_{y}$, are concentrated around the drop part and increase towards the mid points of the four edges of the plate. This understanding of the behaviour of the plate gets enhanced when one gives a look to the cracking patterns predicted theoretically from the nonlinear finite element analysis where, the cracking lines tend to move towards the mid points of the four edges and the cracking zones are concentrated around the four corners of the plate. Another look to the cracking patterns of the plate obtained experimentally and the observations of the experimental records show that, the cracks observed at the bottom surface of the plate at the region between the corners of the drop part and the supporting column in the shape of diagonal cracks perpendicular to the line connecting the drop corner and the neighboring column. With the increase in the applied load, the cracks propagated and new sets of cracks parallel to the earlier ones occurred. With a further increase in the applied load, the developed cracks branched out and moved towards the edges between supports in the two directions and this continued till the complete failure of the plate. This cracking pattern obtained experimentally verifies the earlier one obtained theoretically using the nonlinear finite element approach.

For the plate specimen provided with a drop part located in the area common to the intersection of two column strips (C-C), the normal stresses; $\sigma_{\mathrm{x}} \& \sigma_{\mathrm{y}}$, are found to be concentrated, mainly, along the two middle lines of the plate while, the edges of the drop part absorbs higher values of stresses. The maximum values of normal stresses are developed over a small region at the two edges of the plate far from the drop part. The cracking pattern predicted theoretically using the nonlinear finite element analysis shows also the concentration of cracks along the two middle lines of the plate while, the cracks tend to move towards the plate corner opposite to the drop part. For the tested specimen, bottom flexural cracks were initiated near the center of the plate and gradually propagated towards the middle of the edges between supports in the two directions. Another set of cracks initiated in the bottom surface of the plate; perpendicular to the line connecting two diagonal columns, and propagated in the region around columns.

For plates having drop part located at the intersection of one middle strip and one column strip; (M-C1, M$\mathrm{C} 2$, and M-C3), the normal stresses; $\sigma_{\mathrm{x}}$, are concentrated in the middle region around the $Y$-axis of the plate and has its maximum value at the middle edges of the plate far from the drop part while, the normal stresses; $\sigma_{y}$, are concentrated in the middle region coincides with the $X$-axis while this concentration of stresses gets stopped at the edges of the drop part. The cracking pattern predicted theoretically from the nonlinear finite element analysis of plate $\mathrm{M}-\mathrm{Cl}$ shows the concentration of cracks at the two middle lines of the plate while the experimental results show that the bottom cracks are observed, nearly, at the center of the plate. The cracks branched out and moved towards the edges between supports in the two directions and around the drop part. Another set of diagonal cracks occurred in the bottom region around columns. Both middle and diagonal cracks propagated with the increase in the applied load till the plate failed by the propagation of the middle cracks. As shown in photos, the main crack continues till it divides the plate into approximately two equal parts one of them contains the drop part. For plate specimens (M-C2) and (M-C3), where the size of the drop part is increased, similar cracking patterns are observed while the load carrying capacity of the plate was slightly enhanced. This may be explained as; the column strip, in this case, including the drop part acts as a wide beam attracts more loads and more moments because of its relatively higher stiffness. This, what is called, wide beam was cracked at center of the specimen perpendicular to the beam axis. As 
shown in Table (4), both the cracking and the ultimate loads of the plate have been relatively enhanced with the existence of the drop part. Figure (10) shows a histogram for the ultimate loads predicted theoretically and experimentally for various plate specimens, while Table (5) gives a comparison between both analytical and experimental ultimate loads of various plate specimens.

Load-Deflection Response of Various Plate Specimens

Figures (11-15) show contour lines for the central deflection of various plate specimens (at point P1) while, the variations in the predicted vertical displacements along the plate axes are shown in Figures (16-20) for various plates. As shown in Figure (11), the plate specimen provided with a drop part at the intersection of two middle strips (M-M), shows symmetry in the vertical displacement around the two axes of the plate. When the plate is provided with a drop part in the area common to the intersection of two column strips (C-C), the symmetry of deflection around the two axes is no more valid. Figure (12) shows that, for such plates, a new type of symmetry of the deflection occurs around the line connecting the column coincides with the drop part and the opposite column while the point exhibiting the maximum deflection moves towards the column opposite to that coincides with the drop part. This understanding becomes clearer when we give a look to Fig. (16) where, the variation of vertical displacement along the plate length in the $x$ direction is plotted. As shown in the figure, the plate develops the minimum value of deflection at that edge containing the drop part, while the maximum deflection occurs away from the Y-axis of the plate in the opposite side of the drop part.

For plates provided with drop parts located at the intersection of one middle strip and one column strip; (M-C1, M-C2, and M-C3), the contour lines of vertical displacement shown in Figures (13-15) show the symmetry in the vertical displacement around the plate axis perpendicular to the drop part while the point having the maximum deflection tends to move far from the region containing the drop part. This happened for the three plates; $\mathrm{M}-\mathrm{C} 1, \mathrm{M}-\mathrm{C} 2$, and $\mathrm{M}$ C3. Figures (17), (18) \& (20) show the variation in the vertical displacement along the $\mathrm{X}$-axis of the plate. Again the decrease in the plate deflection at the edge near to the drop part and the increase in that deflection towards the other edge opposite to the drop part are clear. The unsymmetrical distribution of vertical displacement along the plate length is also noticed. The plate develops its maximum deflection in that portion free from drop parts. The same observations are noticed for the three plates. Figure (19) shows the variation in the plate deflection along the $\mathrm{Y}$-axis of plate $\mathrm{M}-\mathrm{C} 2$ where the plate develops symmetric distribution of the vertical deflection along the $y$-axis which does not crop any portion of the drop part.

Figures (21-25) show the load deflection behaviours obtained experimentally and analytically; using the nonlinear finite element approach, for various plate specimens. As shown in figures, the analytical response of various plate specimens tends to be stiffer than the experimental results. This may be understood as an effect of the assumption of perfect bond in the analytical solution, while this is not true in a real structure as some bond slippage usually occurs. Moreover, the existence of supporting columns, in the experimental results, may have some effect on the increase in the plate deflection as the columns have some flexibility and its connection to plates may have some excess rotation which, in turn, increases the plate deflection while this has not been considered in the finite element analysis.

\section{CONCLUSIONS}

Based on the present study, the following conclusions may be drawn:

1. The presence of drop parts has a significant effect on the stress distribution in flat plates. For plates provided with a drop part at the intersection of two middle strips the normal stresses; $\sigma_{x} \& \sigma_{y}$, are concentrated around the drop part and increase towards the mid points of the four edges of the plate. When the plate is provided with a drop part located in the area common to the intersection of two column strips, the normal stresses; $\sigma_{\mathrm{x}} \& \sigma_{\mathrm{y}}$, are found to be concentrated, mainly, along the two middle lines of the plate, while the edges of the drop part absorbs higher values of stresses. The maximum values of normal stresses are developed over a small region at the two edges of the plate far from the drop part. For plates having drop part located at the intersection of one middle strip and one column strip, the normal stresses; $\sigma_{x}$, are concentrated in the middle region containing the $Y$-axis of the plate and has its maximum value at the middle edges of the plate while, the normal stresses; $\sigma_{y}$, are concentrated in the middle region coincides with the $X$-axis while this concentration of stresses gets absorbed by the edges of the drop part. In all specimens there is a stress concentration at the column strips.

2. The presence of drop parts has a significant effect on the cracking patterns of flat plates. As a general notice for all the considered plates, the cracking patterns show extensive cracking on the bottom surface of plates while, the cracks on the top surfaces are concentrated around the supporting columns. The solid plate without drops fails by the propagation of flexural cracks at the two middle lines of the plate. When the plate is provided with 
a drop part at the intersection of two middle strips, the plate fails by the propagation of flexural cracks at the bottom surface of the plate in the region between the corners of the drop part and the supporting column, while the flexural cracks disappeared in the region of the drop. The failure cracks had the shape of diagonal cracks perpendicular to the line connecting the drop corner and the neighboring column. For the plate specimen provided with a drop part located in the area common to the intersection of two column strips, the cracking pattern predicted from the finite element analysis shows also the concentration of cracks along the two middle lines of the plate, while the cracks tend to move towards the plate corner opposite to the drop part. For the tested specimen, bottom flexural cracks were initiated near the center of the plate and gradually propagated towards the middle of the edges between supports in the two directions. Another set of cracks initiated in the bottom surface of the plate; perpendicular to the line connecting two diagonal columns, and propagated in the region around columns. For plates having drop part located at the intersection of one middle strip and one column strip, the cracking pattern predicted theoretically from the nonlinear analysis of plate shows the concentration of cracks at the two middle lines of the plate while the experimental results show that the bottom cracks are observed, nearly, at the center of the plate. The cracks branched out and moved towards the edges between supports in the two directions and around the drop part. The cracks propagated with the increase in the applied load till the plate failed by the propagation of the middle cracks.

3. The presence of drop parts has a significant effect on the vertical displacement of flat plates. As the case of solid flat plates, the plate specimen provided with a drop part at the intersection of two middle strips shows symmetry in the vertical displacement around the two axes of the plate. When the plate is provided with a drop part at the intersection of two column strips, the symmetry of deflection around the two axes is no more valid. For such plates, a new type of symmetry in the deflection occurs around the line connecting the column coincides with the drop part and the opposite column while, the point exhibiting the maximum deflection moves towards the column opposite to that coincides with the drop part. For plates provided with a drop part located at the intersection of one middle strip and one column strip, the contour lines of vertical displacement show the symmetry in the vertical displacement around the plate axis perpendicular to the drop part while the point having the maximum deflection tends to move far from the region containing the drop part.

4. For all the considered plate specimens, the analytical response of various plate specimens tends to be stiffer than the experimental results. This may be understood as an effect of the assumption of perfect bond in the analytical solution while, this not true in a real structure as some bond slippage usually occurs. Moreover, the existence of supporting columns, in the experimental results, may have some effect in the increase in the plate deflection as the columns have some flexibility and its connection to plates may have some excess rotation which, in turn, increases the plate deflection while this has not been considered in the finite element analysis.

5. Good agreement has been obtained between the analytical and the experimental results. Therefore, it may be assumed that the analytical model is capable of predicting the behavior of flat plates with drop part to a satisfactory degree of accuracy.

\section{REFERENCES}

[1] Abd El-Baki O. F., " Behavior and Analysis of Flat Plates with drop part", M. Sc. thesis, Faculty of Engineering, El-Mansoura University, ElMansoura, Egypt, 2002.

[2] Carl Erik Broms., "Elimination of Punching Failure Mode," ACI Journal, Vol.97, No.1, January-February 2000, pp.97-S11.

[3] Egyptian Standard, ES:1109-1971, "Concrete Aggregates from Natural Sources", Egyptian Organization for Standardization and Quality Control, Egypt, 1971.

[4] Egyptian Standard, ES: 1658-1993, "Testing Concrete", Egyptian Organization for Standardization and Quality Control, Egypt, 1993.

[5] Egyptian Standard, ES: 2421-1993, "CementPhysical and Mechanical Testing", Egyptian Organization for Standardization and Quality Control, Egypt, 1993.

[6] Egyptian Code for Design and Construction of Reinforced Concrete Structures, Ministry of Housing and Urbanization, (EGCP-1995), Fourth Edition, Cairo, Egypt, 1998.

[7] Egyptian Code for Design and Construction of Reinforced Concrete Structures, Ministry of Housing and Urbanization, (ECCS 203-2001), Second Revision, Eighth Edition, Cairo, Egypt, 2001.

[8] Egyptian Code for Design and Construction of Reinforced Concrete Structures, Ministry of Housing and Urbanization, (ECCS 203-2003), Second Revision, Eighth Edition, Cairo, Egypt, 2003. 
[9] EI-Salakawy, E. F., Polak, M. A. and Soliman, M. H., "Reinforced Concrete Slab-Column Edge Connections with Openings", ACI Journal, Vol.97, No.3, January-February 1999, pp.79-\$9.

[10] Ghali, A. and Megally, S., "Design for Punching Shear Strength with ACI 318-95", ACI Journal, Vol. 96, No.4, July-August 1999, pp. 539-560.
[11] Willam, K. J., and Warnke, E. D., "Constitutive Model for the Triaxial Behaviour of Concrete", Proceedings, International Association for Bridge and Structural Engineering, Vol. 19, ISMES, Bergamo, Italy, p. 174, 1975.

Table 1 Details of the Tested Plate Specimens

\begin{tabular}{|c|c|c|c|c|c|c|c|c|c|c|}
\hline \multirow{2}{*}{$\begin{array}{c}\text { Slab } \\
\text { Model }\end{array}$} & \multirow{2}{*}{$\begin{array}{c}\mathbf{L} \\
(\mathbf{c m})\end{array}$} & \multicolumn{2}{|c|}{$\begin{array}{c}\text { Drop } \\
\text { Dimensions }\end{array}$} & \multicolumn{2}{|c|}{ Drop Ratio } & \multicolumn{2}{|c|}{$\begin{array}{c}\text { Position of the } \\
\text { Drop Part }\end{array}$} & \multirow{2}{*}{$\begin{array}{c}\text { Drop } \\
\text { Height } \\
\text { d (cm) }\end{array}$} & \multirow{2}{*}{$\begin{array}{c}\text { Drop at the } \\
\text { Intersection } \\
\text { of }\end{array}$} & \multirow[t]{2}{*}{ Reinforcement } \\
\hline & & $\mathrm{a}(\mathrm{cm})$ & b (cm) & $\alpha_{x}=a / L$ & $\alpha_{Y}=b / L$ & $\mathbf{X}(\mathbf{c m})$ & $Y(\mathrm{~cm})$ & & & \\
\hline So & 125 & 0.000 & 0.000 & 0.000 & 0.000 & 0.000 & 0.000 & 0.00 & No drop & $1 \phi 3.4 \mathrm{~mm} @ 5 \mathrm{~cm}$ \\
\hline $\mathrm{M}-\mathrm{M}$ & 125 & 62.500 & 62.500 & 0.500 & 0.500 & 31.25 & 31.25 & 7.50 & $2 \mathrm{M}$ - Strips & $1 \phi 3.4 \mathrm{~mm} @ 5 \mathrm{~cm}$ \\
\hline $\mathrm{M}-\mathrm{Cl}$ & 125 & 15.625 & 31.250 & 0.125 & 0.250 & 15.00 & 46.90 & 7.50 & M -C Strips & $1 \phi 3.4 \mathrm{~mm} @ 5 \mathrm{~cm}$ \\
\hline $\mathrm{M}-\mathrm{C} 2$ & 125 & 21.250 & 46.875 & 0.170 & 0.375 & 10.00 & 39.05 & 7.50 & $\mathrm{M}-\mathrm{C}$ Strips & $1 \phi 3.4 \mathrm{~mm} @ 5 \mathrm{~cm}$ \\
\hline $\bar{M}-\mathrm{C} 3$ & 125 & 31.250 & 62.500 & 0.250 & 0.500 & 0.000 & 31.25 & 7.50 & M -C Strips & $1 \phi 3.4 \mathrm{~mm} @ 5 \mathrm{~cm}$ \\
\hline $\mathrm{C}-\mathrm{C}$ & 125 & 31.250 & 31.250 & 0.250 & 0.250 & 0.000 & 0.000 & 7.50 & $2 \mathrm{C}-$ Strips & $1 \phi 3.4 \mathrm{~mm} @ 5 \mathrm{~cm}$ \\
\hline
\end{tabular}

$M=$ Middle Strip \& $C=$ Column Strip

Table 2 Mix Proportions of Plain Concrete

\begin{tabular}{|l|c|c|c|c|c|}
\hline & Cement & Sand & Gravel & Water & Water/Cement Ratio \\
\hline Material Weights $\left(\mathrm{kg} / \mathrm{m}^{3}\right)$ & 400 & 650 & 1150 & 200 & 0.50 \\
\hline
\end{tabular}

Table 3 Test Results of the Reinforcing Steel Wires

\begin{tabular}{|c|c|c|c|c|c|c|}
\hline \multirow{2}{*}{$\begin{array}{c}\text { Diameter } \\
(\mathrm{mm})\end{array}$} & \multicolumn{2}{|c|}{ Average Strength $\left(\mathrm{Kg} / \mathrm{cm}^{2}\right)$} & \multicolumn{2}{|c|}{ Tensile Strength $\mathbf{( K g / \mathrm { cm } ^ { 2 } )}$} & \multicolumn{2}{|c|}{ Elongation \% } \\
\cline { 2 - 7 } & Result & Code Limit & Result & Code Limit & Result & Code Limit \\
\hline 3.4 & 2550 & 2400 & 3700 & 3500 & $22 \%$ & $20 \%$ \\
\hline
\end{tabular}

Table 4 Experimental Values of Cracking and Ultimate Loads of Various Plate Specimens

\begin{tabular}{|c|c|c|c|c|c|c|c|c|c|c|}
\hline \multirow{2}{*}{ Model } & \multicolumn{2}{|c|}{ Drop Ratio } & \multirow{2}{*}{$\begin{array}{c}\text { Drop Height } \\
\text { d (cm) }\end{array}$} & \multicolumn{3}{|c|}{ Cracking Load $P_{\mathrm{er}}$} & \multicolumn{3}{|c|}{ Ultimate Load $P_{u}$} & \multirow{2}{*}{$\mathbf{P}_{\mathrm{cr}} / \mathbf{P}_{\mathrm{u}}$} \\
\hline & $\alpha_{X}=a / L$ & $\alpha_{Y}=b / \mathbf{L}$ & & ton & $\operatorname{ton} / \mathrm{m}^{2}$ & $\% \mathrm{~S}_{0}$ & ton & $\operatorname{ton} / \mathrm{m}^{2}$ & $\% \mathrm{~S}_{\mathrm{n}}$ & \\
\hline So & 0.000 & 0.000 & 0.00 & 2.60 & 1.664 & 1.00 & 6.30 & 4.032 & 1.00 & 0.41 \\
\hline $\mathrm{M}-\mathrm{M}$ & 0.500 & 0.500 & 7.50 & 3.20 & 2.048 & 1.23 & 7.80 & 4.992 & 1.24 & 0.41 \\
\hline $\mathrm{C}-\mathrm{C}$ & 0.250 & 0.250 & 7.50 & 2.75 & 1.760 & 1.06 & 7.00 & 4.480 & 1.11 & 0.39 \\
\hline $\mathrm{M}-\mathrm{Cl}$ & 0.125 & 0.250 & 7.50 & 2.60 & 1.664 & 1.00 & 6.30 & 4.032 & 1.00 & 0.41 \\
\hline $\mathrm{M}-\mathrm{C} 2$ & 0.170 & 0.375 & 7.50 & 2.70 & 1.728 & 1.04 & 6.85 & 4.384 & 1.09 & 0.39 \\
\hline $\mathrm{M}-\mathrm{C} 3$ & 0.250 & 0.500 & 7.50 & 2.75 & 1.760 & 1.06 & 6.85 & 4.384 & 1.09 & 0.40 \\
\hline
\end{tabular}

Table 5 Comparison Between the Experimental and Finite Element Values of Failure Load

\begin{tabular}{|c|c|c|c|c|c|}
\hline \multirow{2}{*}{ Slab Model } & \multicolumn{2}{|c|}{ PEXP } & \multicolumn{2}{c|}{ PFEM } & \multirow{2}{*}{ PEXP / PFEM } \\
\cline { 2 - 5 } & $\left(\mathbf{t} / \mathbf{m}^{2}\right)$ & ton & $\left(\mathbf{t}^{2} \mathbf{m}^{2}\right)$ & ton & 1.22 \\
\hline M-M & 4.992 & 7.800 & 4.092 & 6.394 & 1.18 \\
\hline C-C & 4.480 & 7.000 & 3.797 & 5.933 & 1.14 \\
\hline M-C1 & 4.032 & 6.300 & 3.537 & 5.527 & 1.20 \\
\hline M-C2 & 4.384 & 6.850 & 3.653 & 5.708 & 1.19 \\
\hline
\end{tabular}

$\mathbf{P}_{\mathrm{EXP}}=$ Experimental Value of the Failure Load \& $\mathbf{P}_{\mathrm{FEM}}=$ Finite Element Failure Value of the Failure Load 


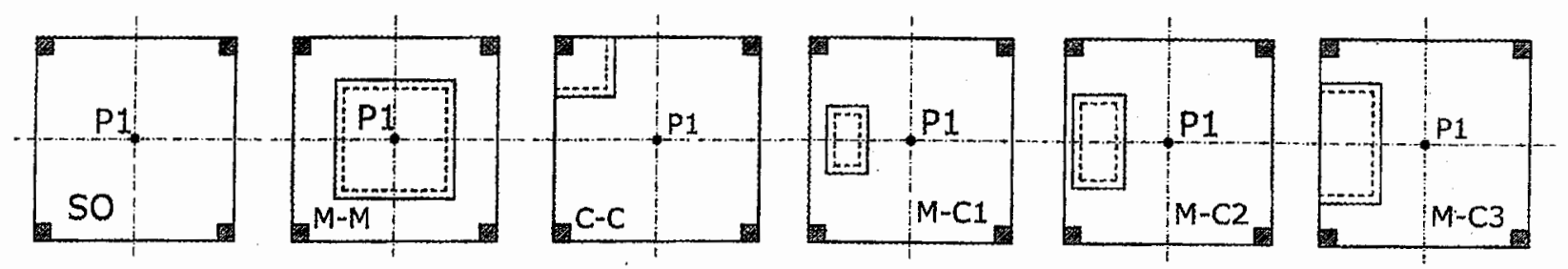

Fig. 1 Configurations of Various Plate Specimens Considered in the Experimental Study
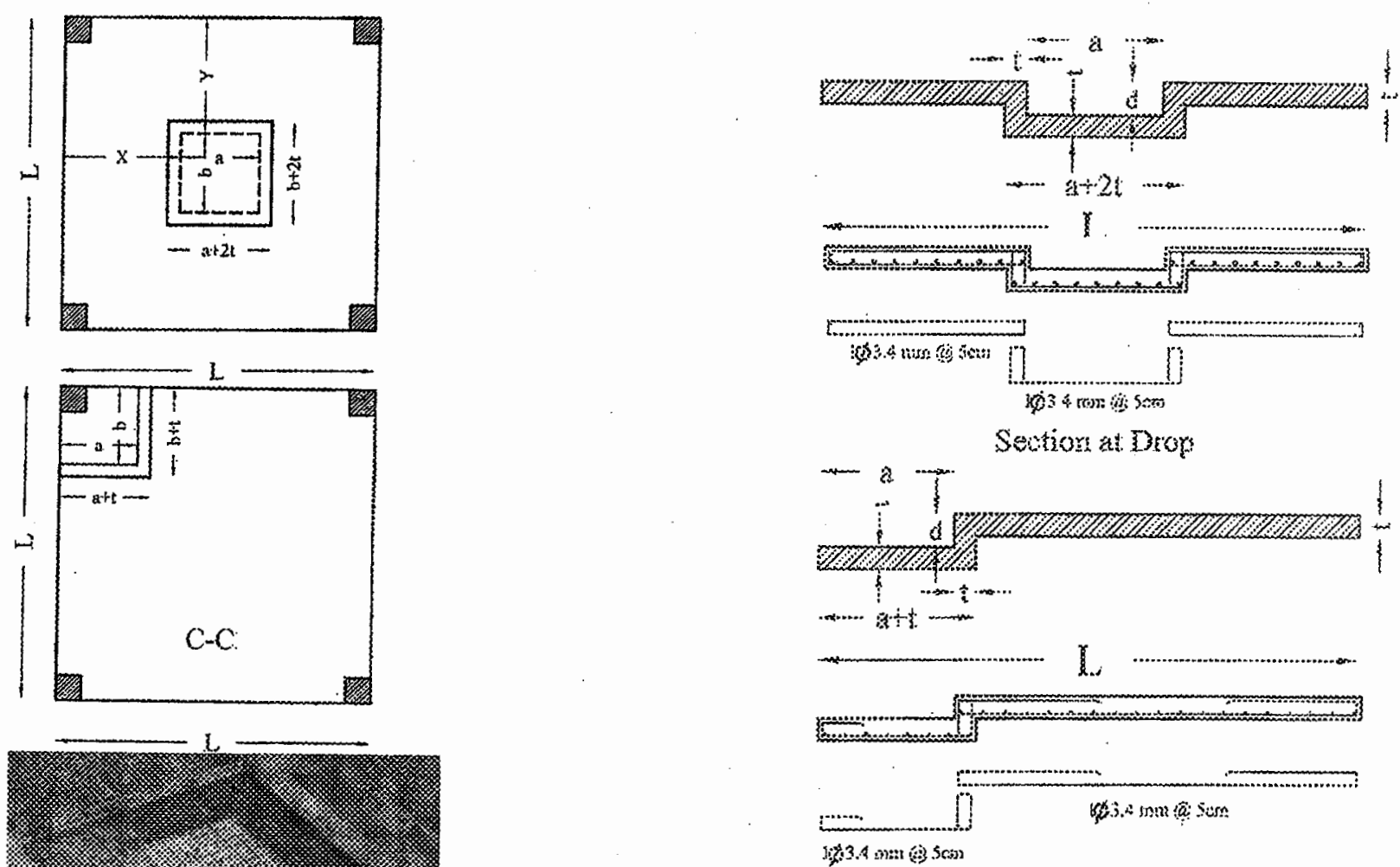

Secton at brop

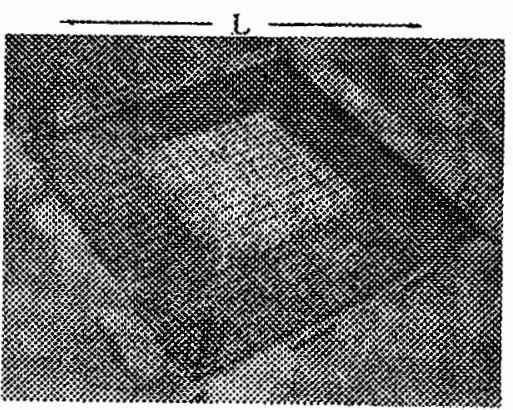

1

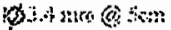

Section in trate

Fig. 2 Configurations of Plate Specimens

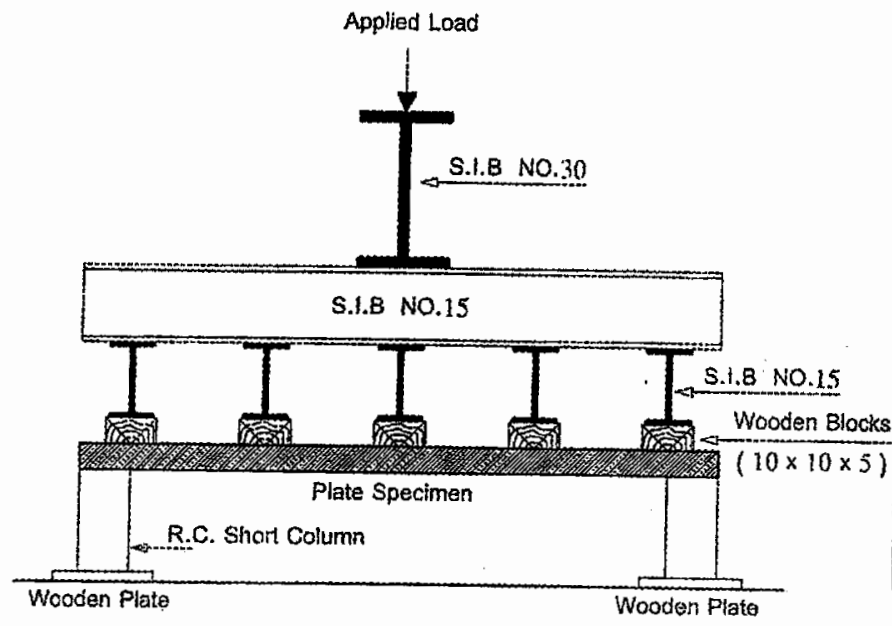

Fig. 3 Experimental Test Set Up

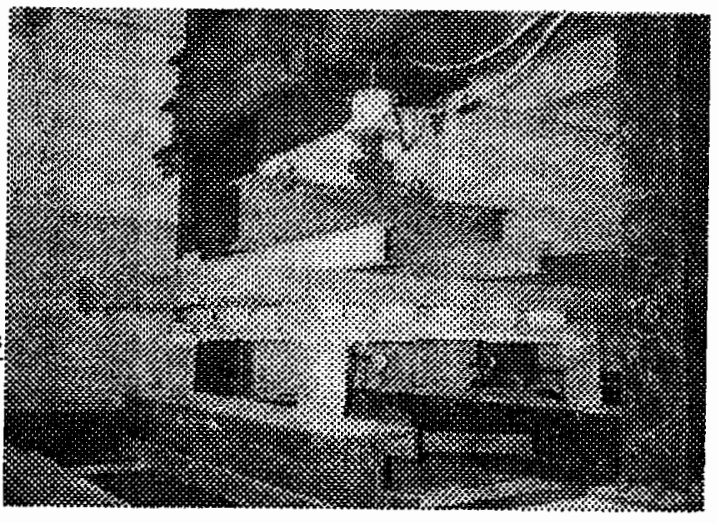

Plate (1) Experimental Test Set Up 
Mohamed H. Matthana, Attia H. Bayomy,A.H. Abdel-Reheem,Ayman Mashaly, "Behoviour of Reinforced ... "
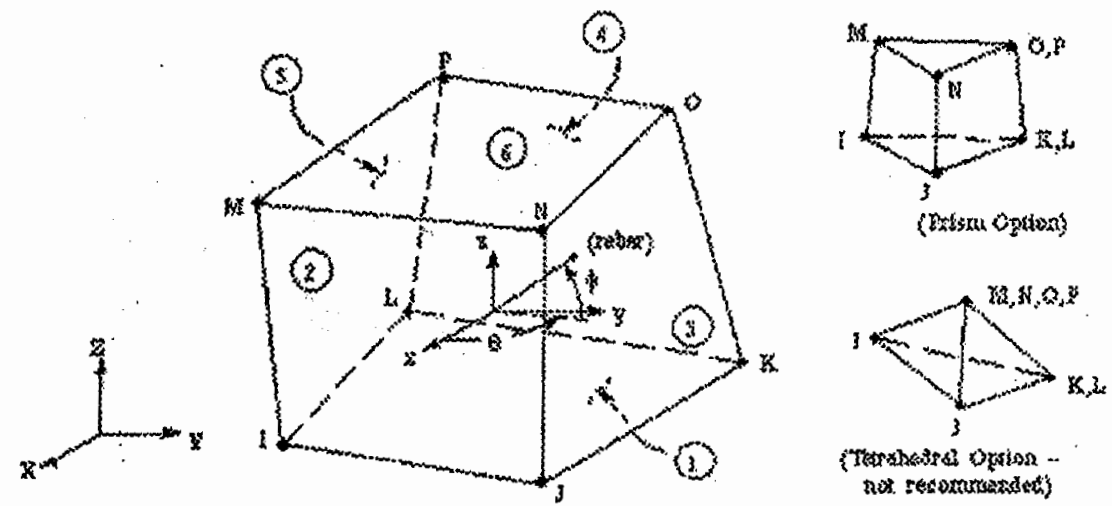

Fig. 4 Details of the Element Used in the Finite Element Analysis
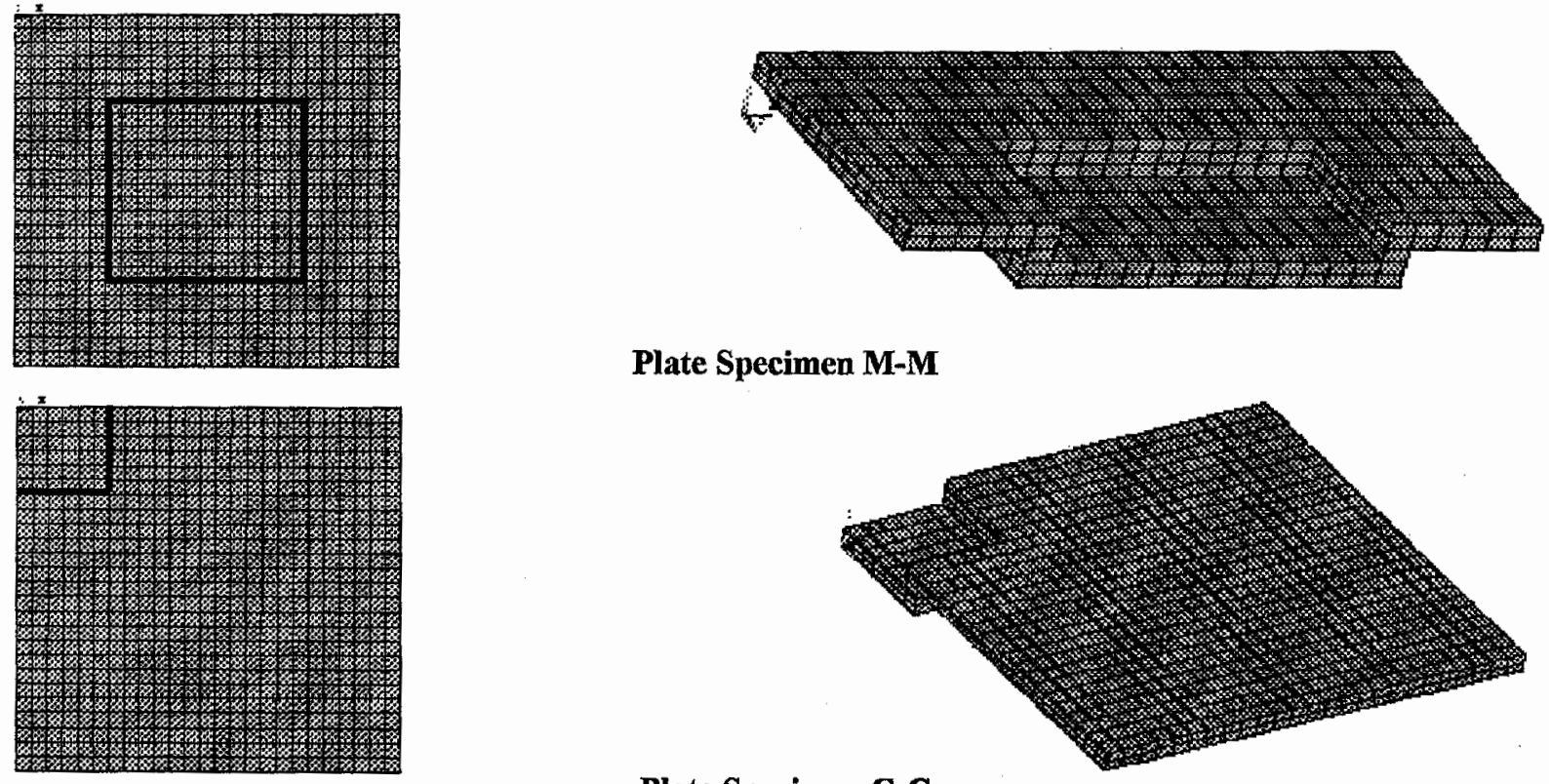

Plate Specimen M-M

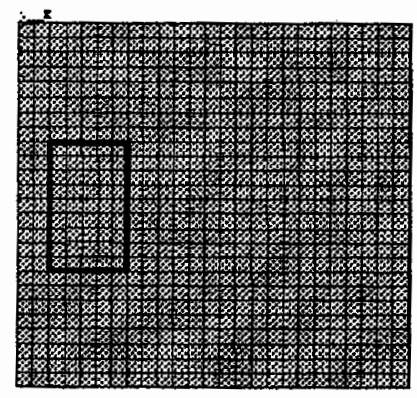

Plate Specimen C-C
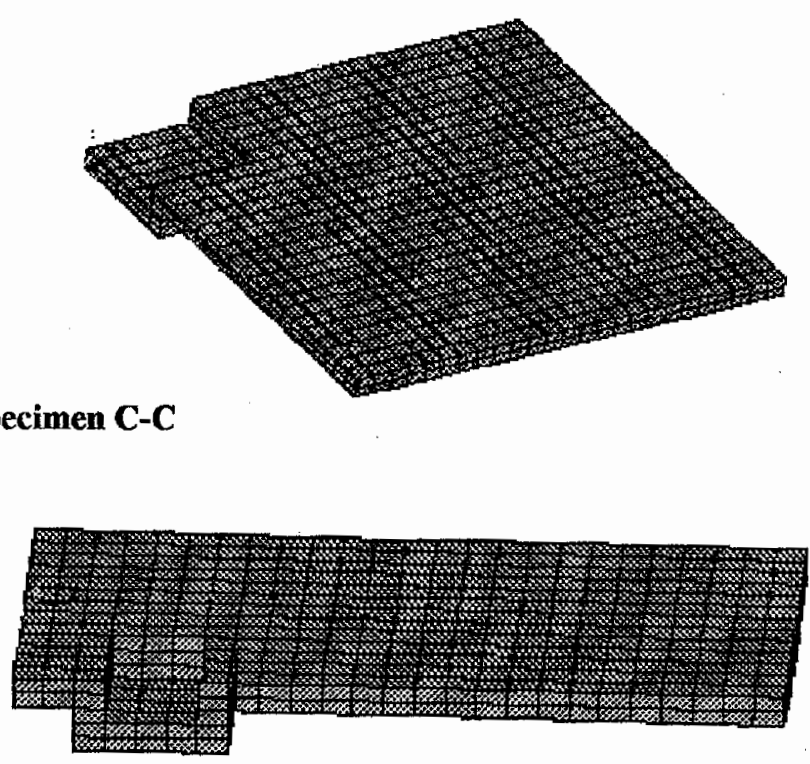

Plate Specimen M-C1
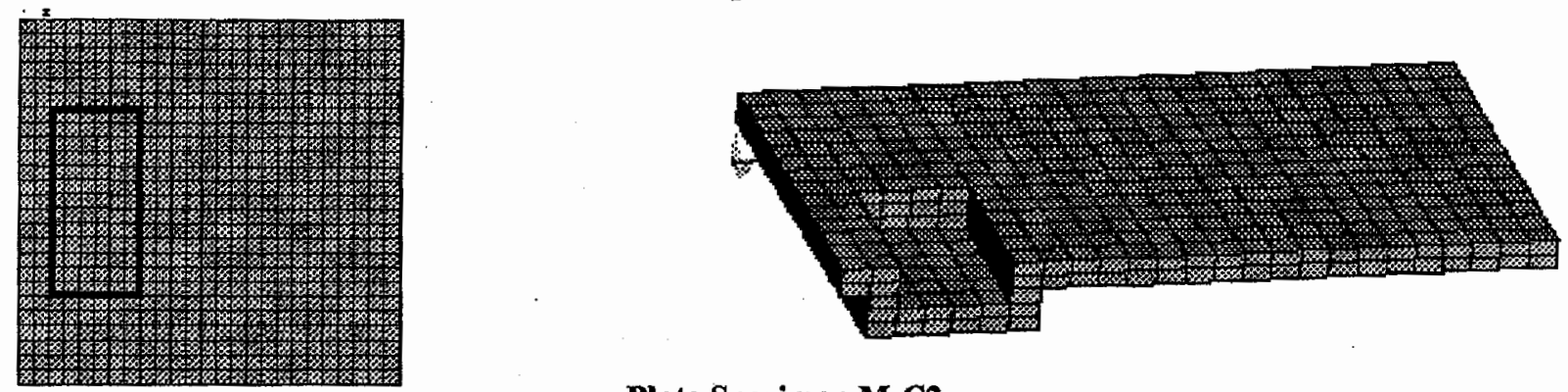

Plate Specimen M-C2 

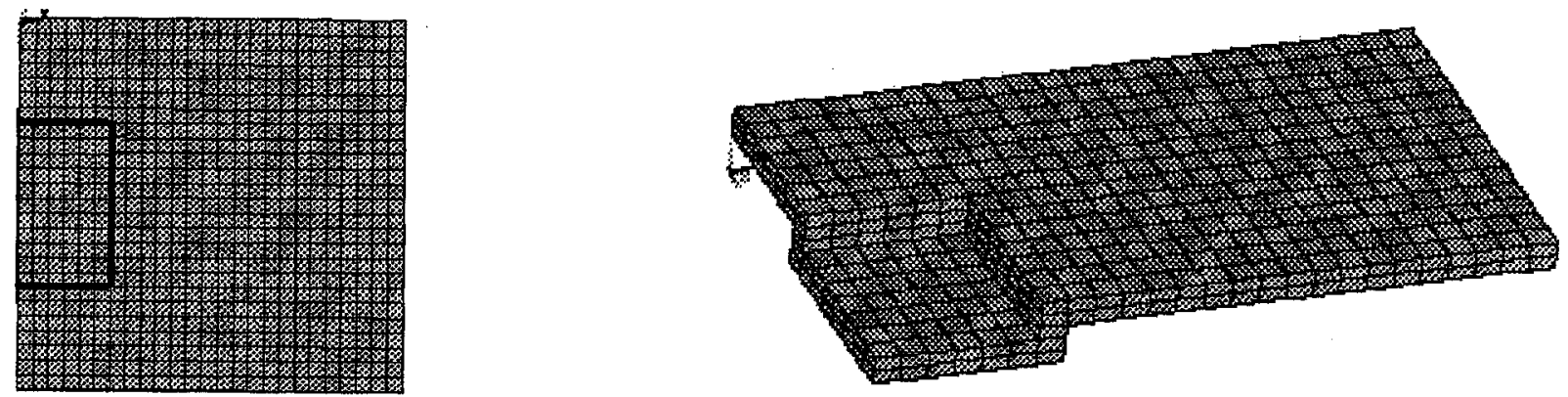

Plate Specimen M-C3

Fig. 5 Finite Element Meshes of Various Plate Specimens

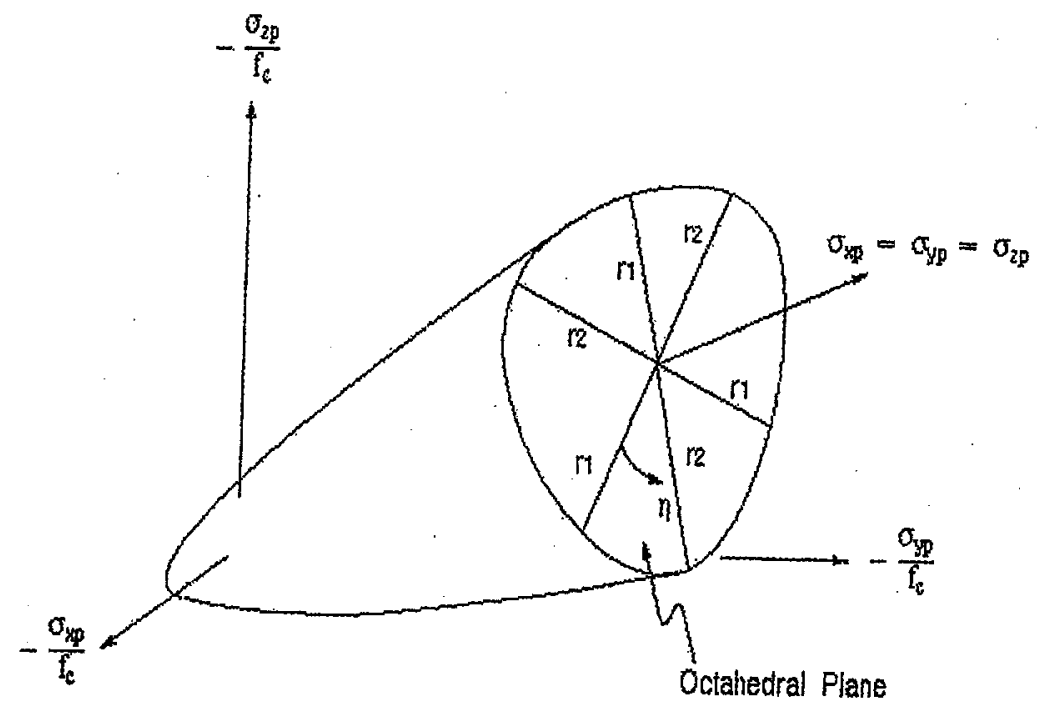

Fig. 6 Failure Surface in Principle Stress Space

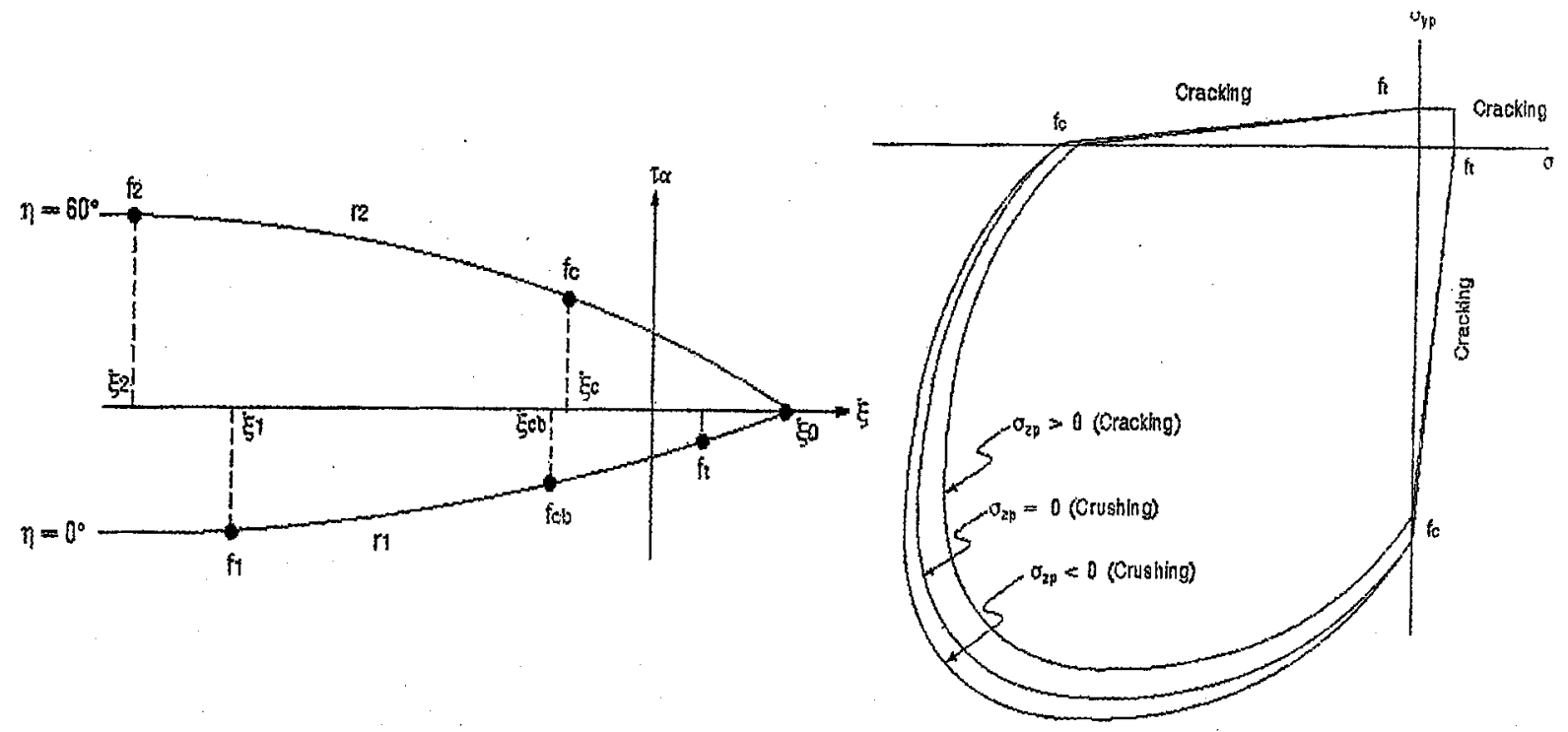

Fig. 7 A Profile of the Failure Surface as a Function of $\zeta$

Fig. 8 Failure Surface in Principle Stress Space (Biaxial State of Stress with sZP Close to Zero) 







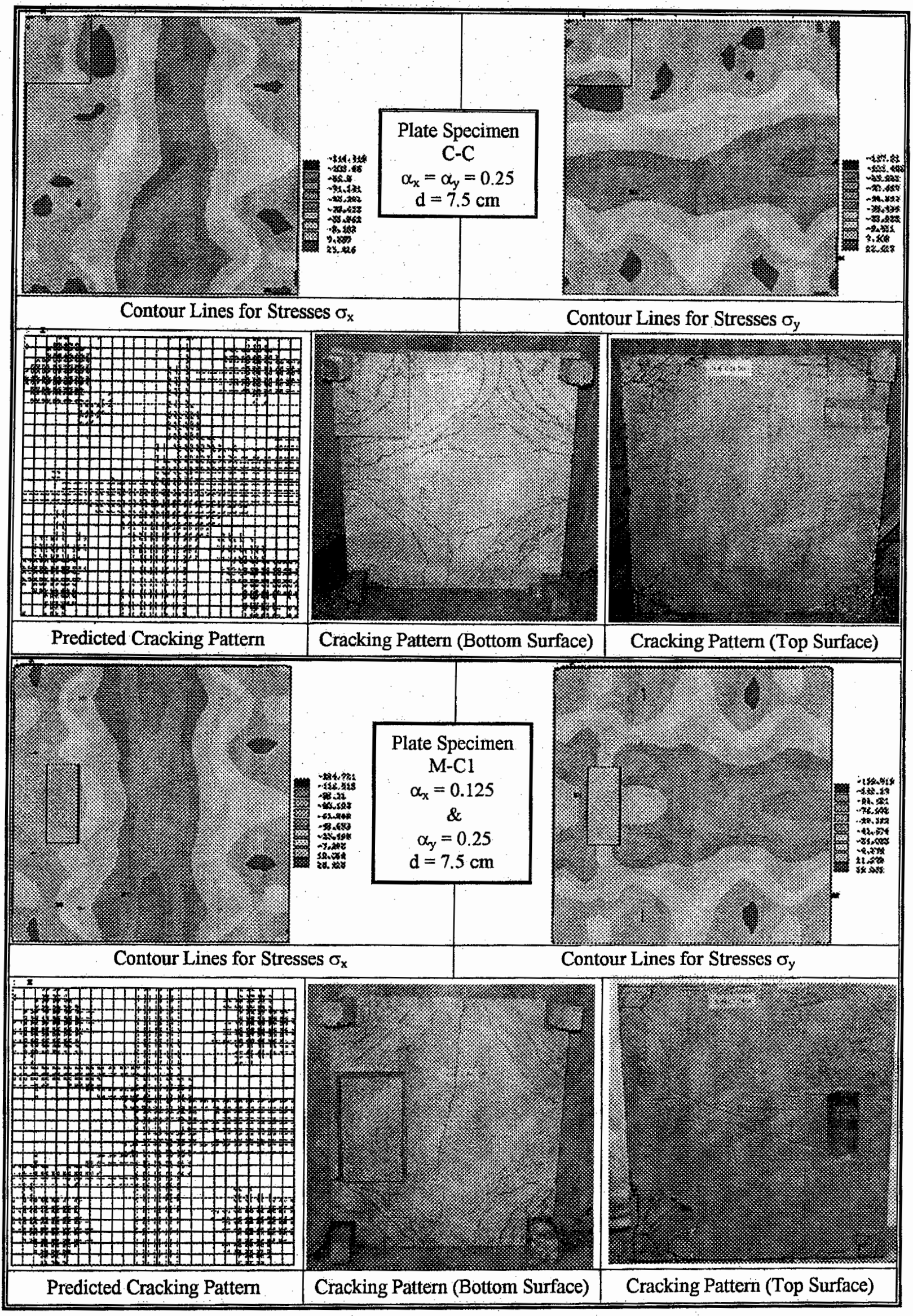




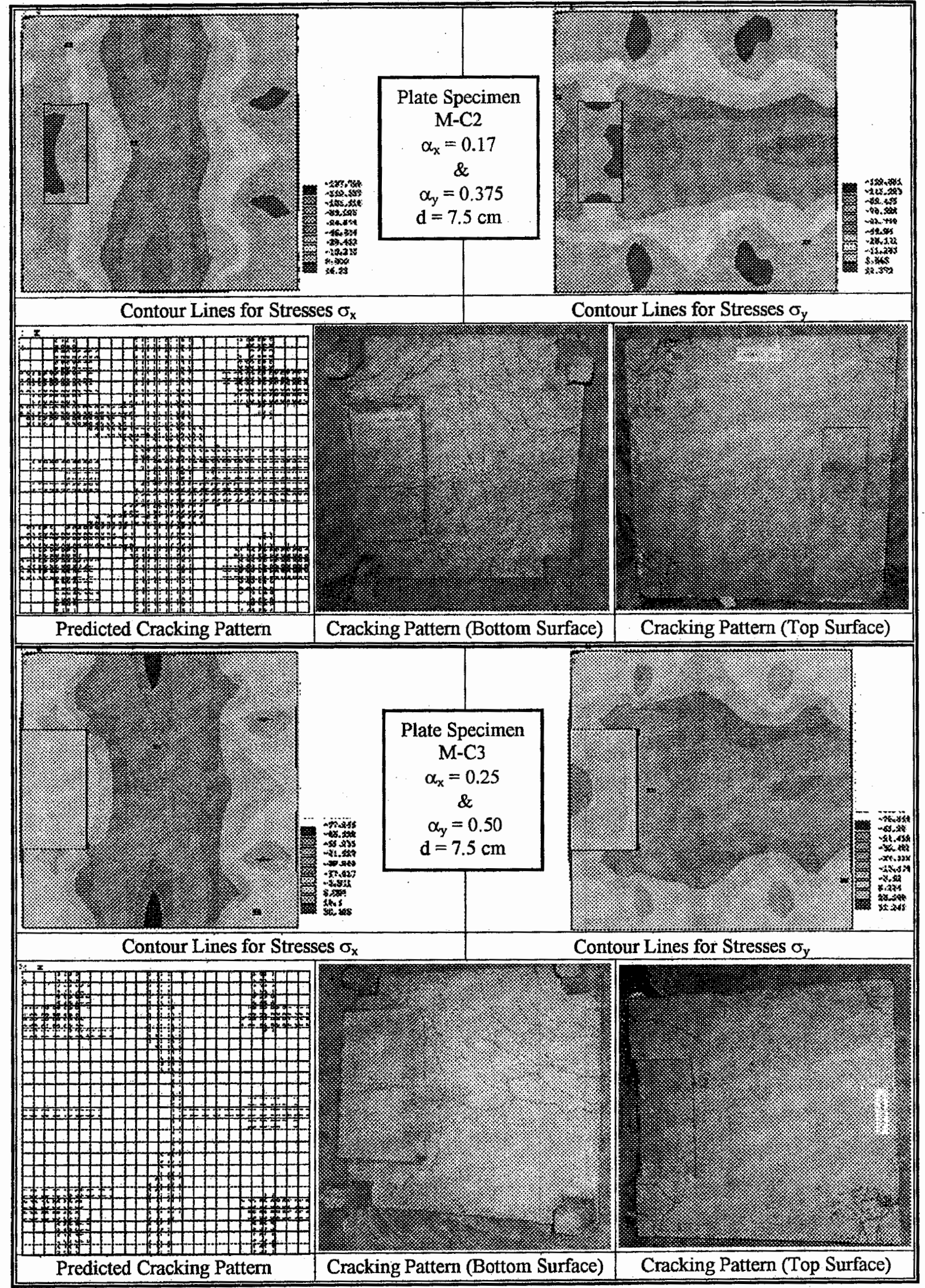

Fig. 9 Stresses Distributions, and Cracking Patterns of Various Plate Specimens 


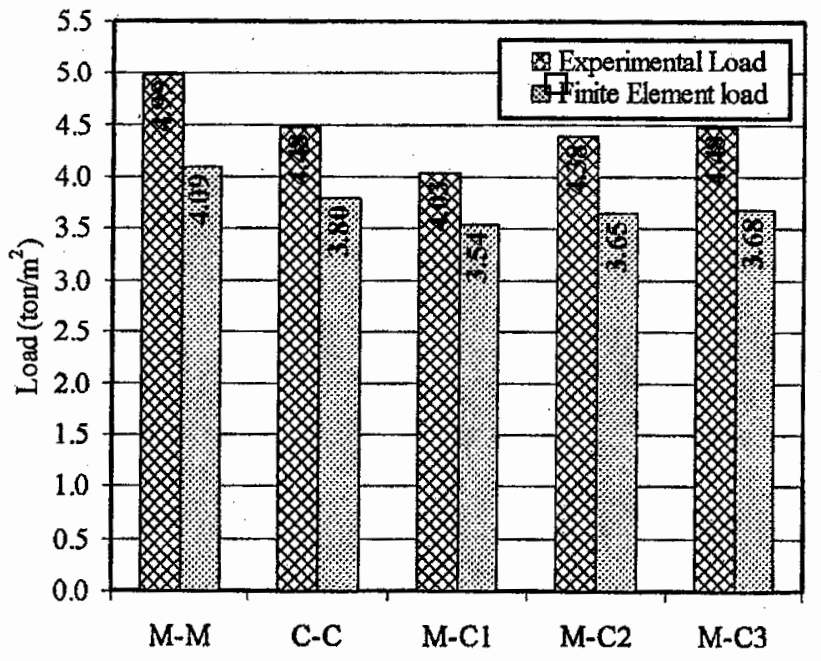

Fig. 10 Experimental and Analytical Values of Ultimate Loads of Various Plates

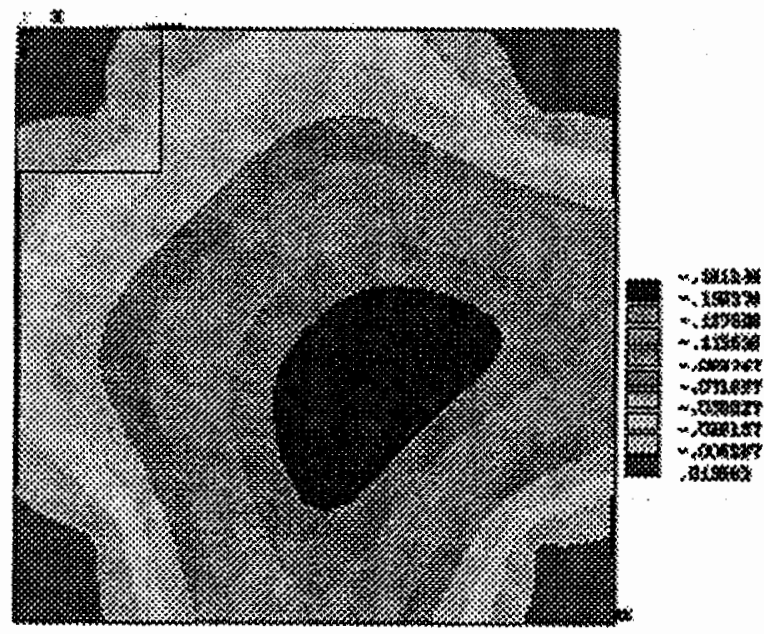

Fig. 12 Contour Lines for the Deflection of Plate Specimen C-C
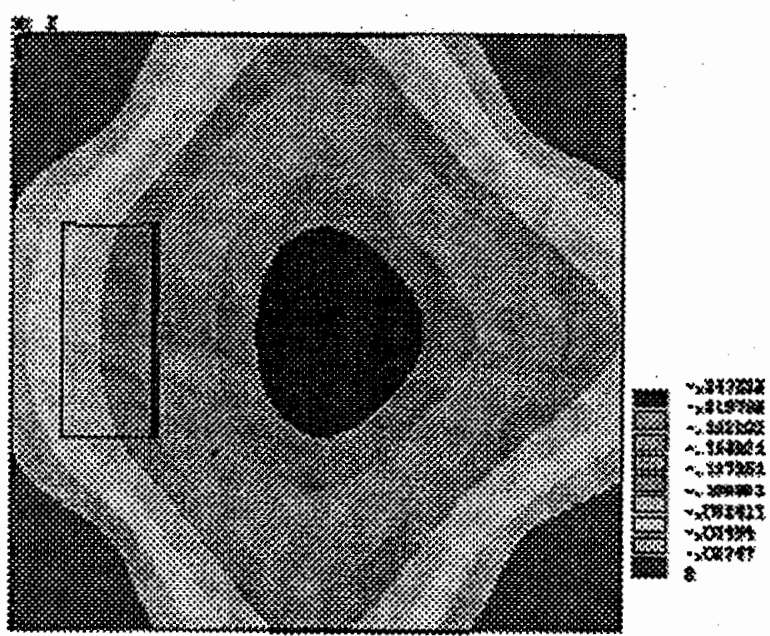

Fig. 14 Contour Lines for the Deflection of Plate Specimen M-C2

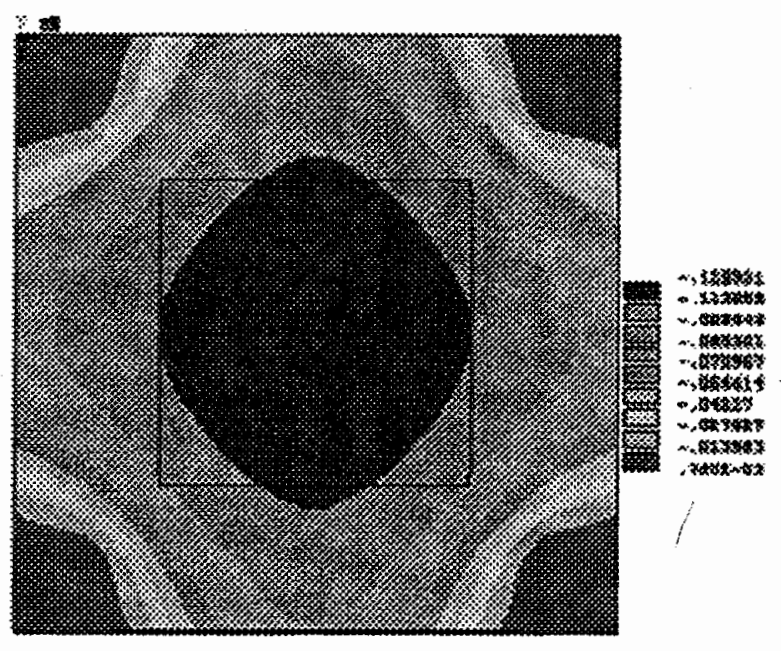

Fig. 11 Contour Lines for the Deflection of Plate Specimen M-M

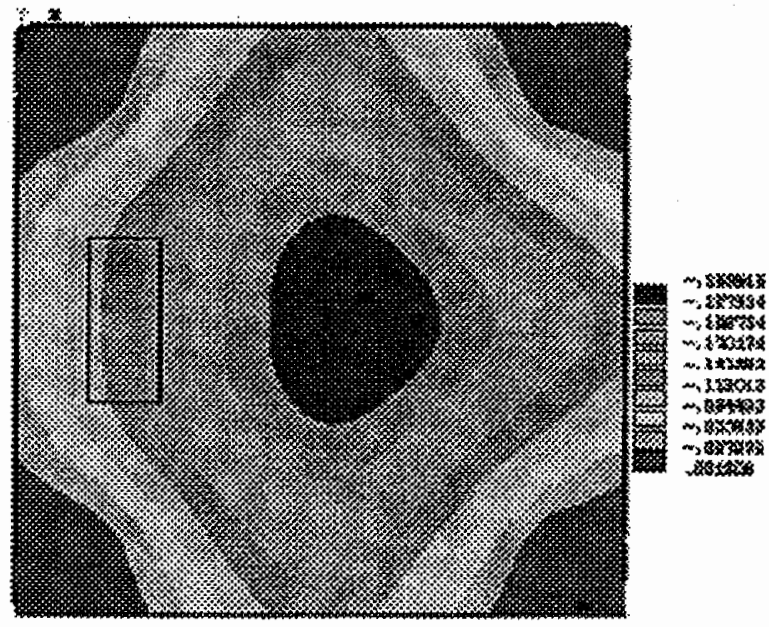

Fig. 13 Contour Lines for the Deflection of Plate Specimen $\mathrm{M}-\mathrm{Cl}$

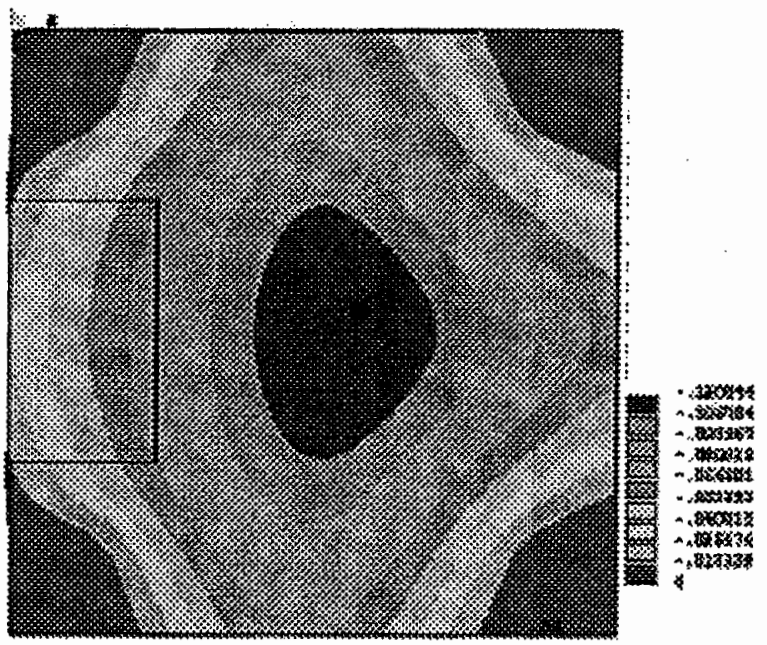

Fig. 15 Contour Lines for the Deflection of Plate Specimen M-C3 


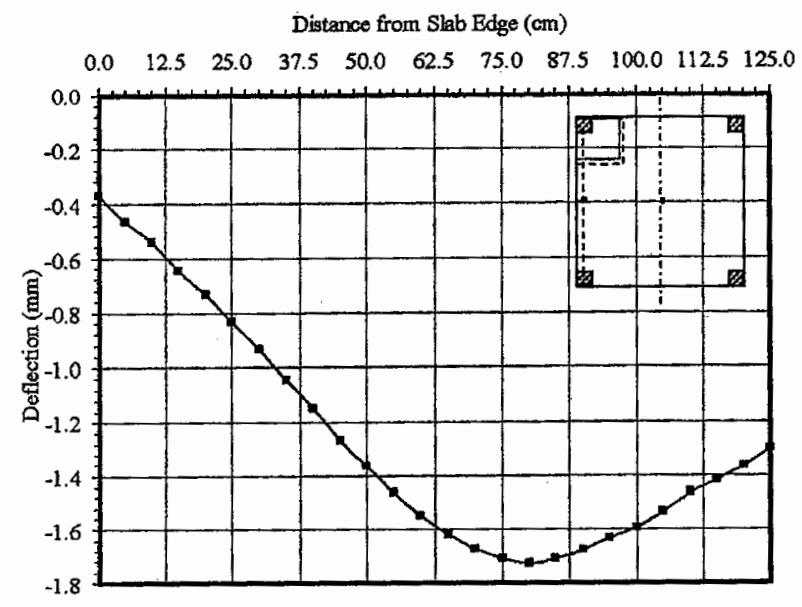

Fig. 16 Variation of Deflection along the length of plate specimen C-C

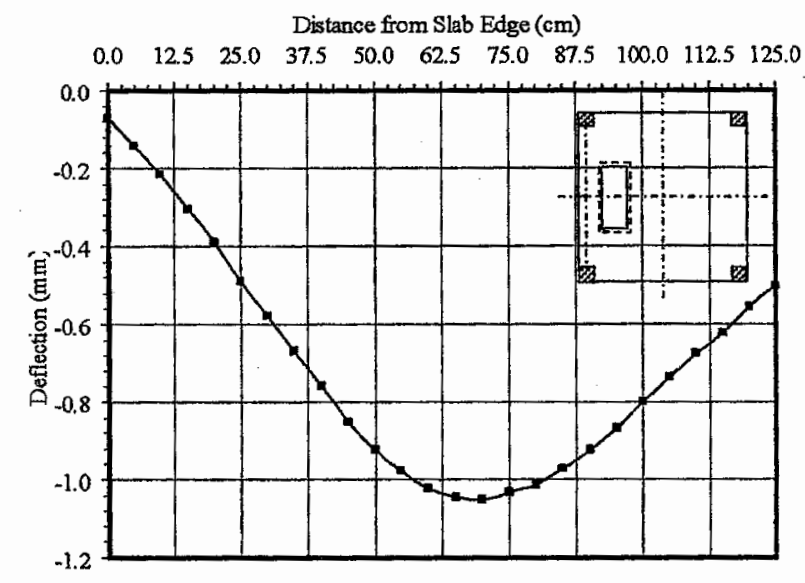

Fig. 18 Variation of Deflection along the X-Axis of plate specimen $\mathrm{M}-\mathrm{C} 2$

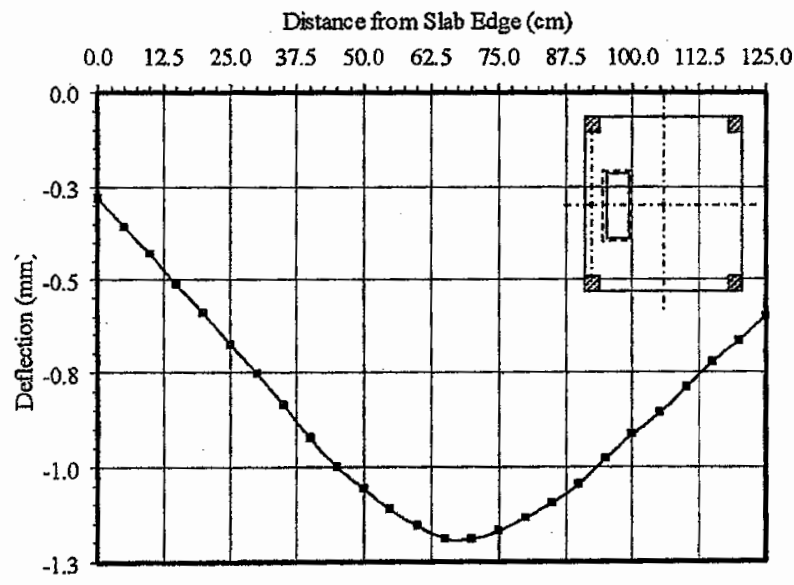

Fig. 20 Variation of Deflection along the length of plate specimen M-C3

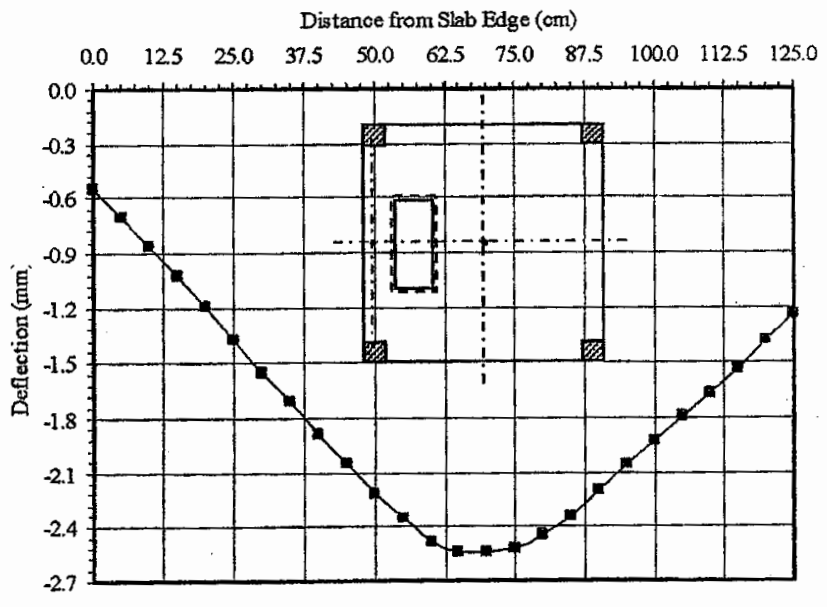

Fig, 17 Variation of Deflection along the length of plate specimen $\mathrm{M}-\mathrm{Cl}$

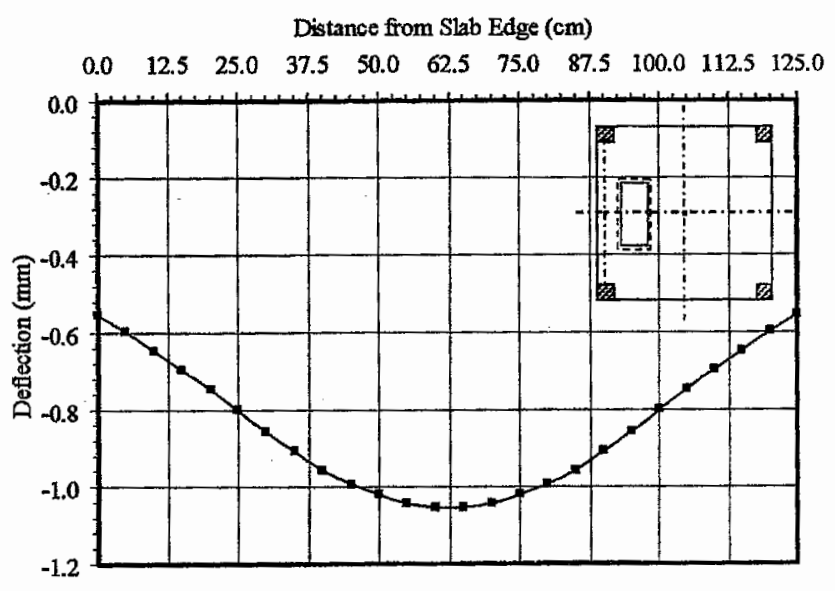

Fig. 19 Variation of Deflection along the Y-Axis of plate specimen $\mathrm{M}-\mathrm{C} 2$ 


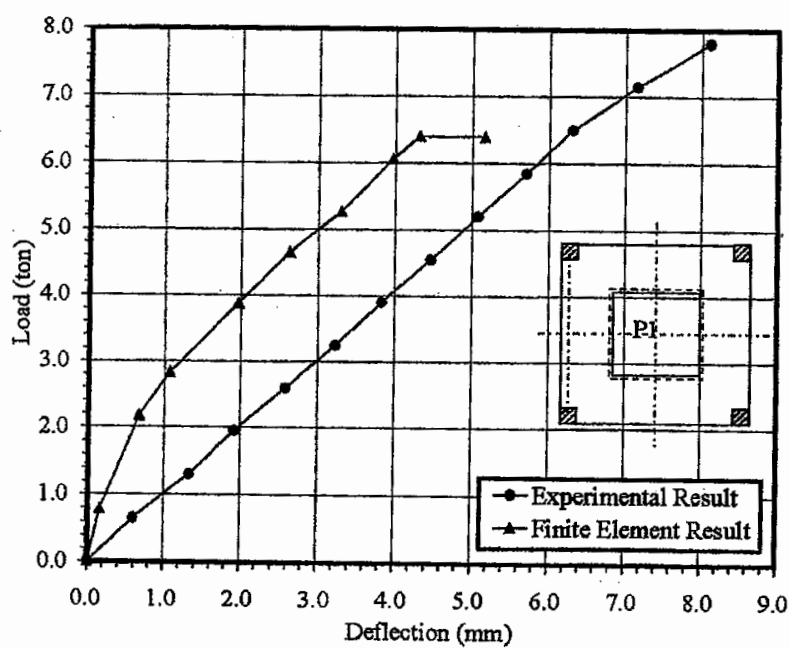

Fig. 21 Load-Deflection Relationship at Point P1 For Plate Specimen M-M

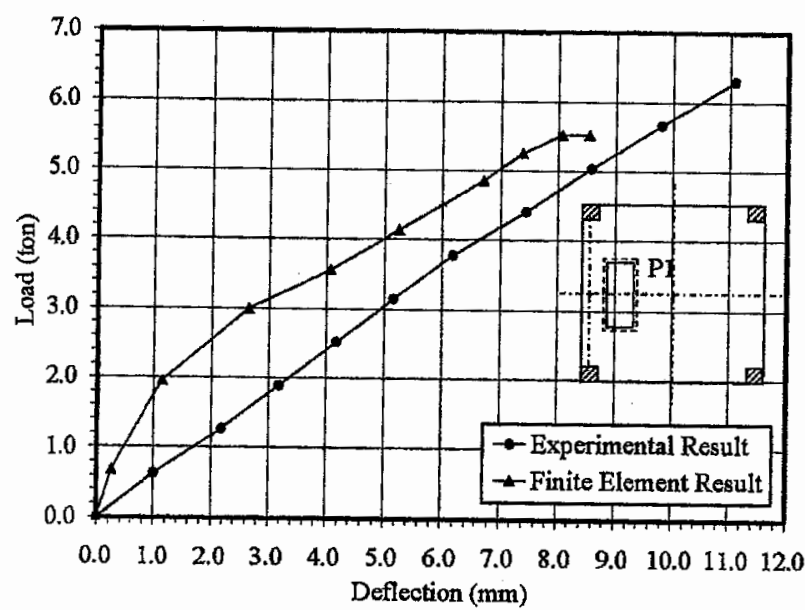

Fig. 23 Load-Deflection Relationship at Point P1 For Plate Specimen M-C1

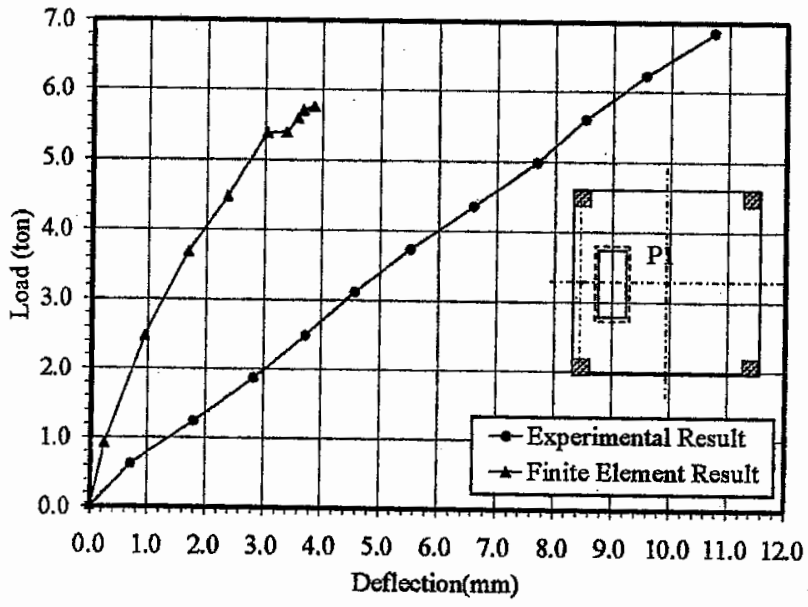

Fig. 25 Load-Deflection Relationship at Point P1 For Plate Specimen M-C3

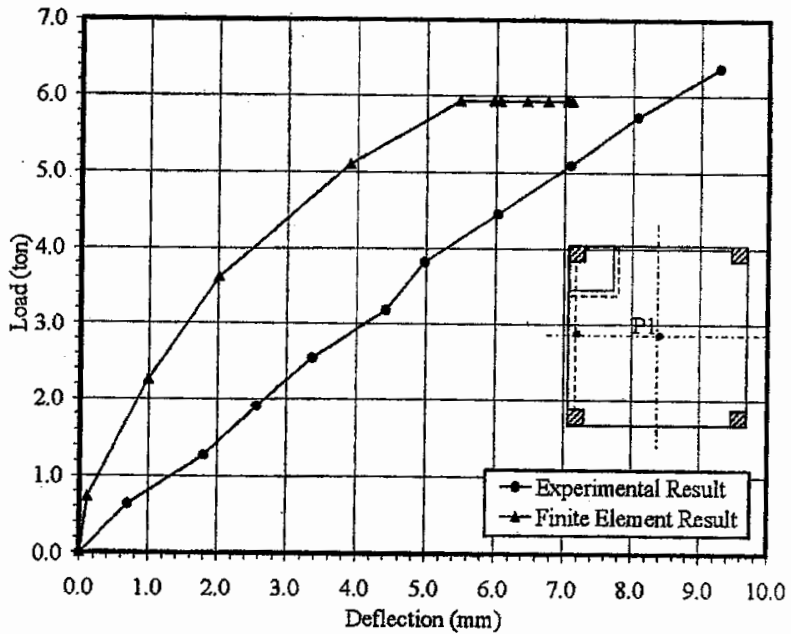

Fig. 22 Load-Deflection Relationship at Point P1 For Plate Specimen C-C

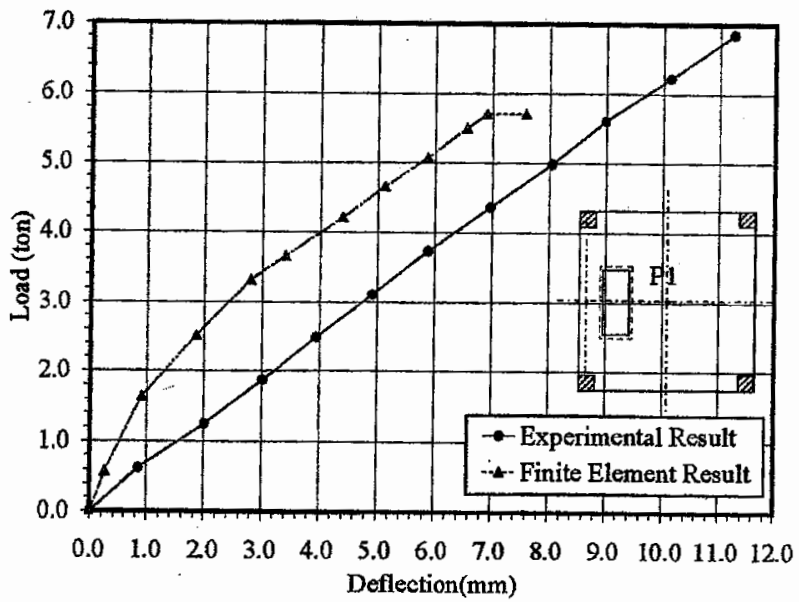

Fig. 24 Load-Deflection Relationship at Point P1 For Plate Specimen M-C2 